\title{
Synergistic Redox Reaction for Value-Added Organic Transformation via Dual-Functional Photocatalytic Systems
}

Weike Shang $^{a}$, Yuangang Li ${ }^{a}{ }^{*}$, Haowei Huang ${ }^{b}$, Feili Lai $^{c}$, Maarten B. J. Roeffaers ${ }^{b}$, Bo Weng ${ }^{b} *$

${ }^{a}$ College of Chemistry and Chemical Engineering, Xi' an University of Science and Technology, No. 58, YanTa Road, Xi'an 710054, P. R. China.

${ }^{b}$ cMACS, Department of Microbial and Molecular Systems, KU Leuven, Celestijnenlaan 200F, 3001 Leuven, Belgium

${ }^{c}$ Department of Chemistry, KU Leuven, Celestijnenlaan 200F, 3001 Leuven, Belgium

*To whom correspondence should be addressed

E-mail:liyuangang@xust.edu.cn; bo.weng@kuleuven.be 


\begin{abstract}
Photocatalytic selective organic transformations provide an efficient synthetic alternative for several industrially relevant chemicals using solar rather than thermal energy. However, in most cases, photocatalytic organic reaction systems involve only reductive or oxidative pathways with the aid of sacrificial reagents as efficient electron acceptors or donors, thus limiting the economic added value. Recently, merging selective organic reductions and oxidations in a dual-functional photocatalytic reaction system has been put forward to tackle this limitation. In this coupled reaction system, both the photogenerated electrons and holes can be simultaneously utilized to generate value-added products, make the overall process more valuable from the economic perspective. In this review, the development of dualfunctional photocatalytic organic synthesis is systemically summarized. Particular emphasis is paid to merging selective organic oxidation and reduction reactions and coupling selective organic transformations with chemical fuel generation (e.g., $\mathrm{H}_{2}, \mathrm{CO}$ ). Also, a personal perspective on future developments in this field is provided. Although still in its infancy, it is expected that this dual-functional technology offers opportunities to develop the next-generation selective organic transformation processes that meet the stringent economic, societal, and ecological expectations.
\end{abstract}

Keyword: Selective organic transformations; value-added organic products; dual-functional photocatalytic systems; chemical fuel generation; photocatalysis 


\section{Introduction}

Heterogeneous catalysis occupies a prominent place in the industrial generation of many organic chemicals, ${ }^{1-4}$ such as pharmaceuticals, pesticides, and food additives. However, conventional synthetic processes for many necessary organic chemicals generally require harsh operating conditions (e.g., high pressure and temperature) and involve environmentally harmful and dangerous stoichiometric oxidants or reducing agents, such as $\mathrm{Cr}^{6+}, \mathrm{MnO}_{4}^{-}$and $\mathrm{H}_{2}$. Besides consuming excessive amounts of energy, these traditional processes also generate many unwanted side products and significant amounts of waste. ${ }^{5-7}$ Thus, developing efficient and environmentally benign synthetic protocols toward selective organic transformations is desirable. Compared with the conventional thermally-driven catalytic processes used for organic synthesis, photocatalysis provides a green alternative. Over the past decades, photocatalysis has matured in virtue of its potential to develop sustainable chemical processes with a minimal environmental impact. ${ }^{8-13}$ Additionally, the energy supplied by the incident photons enables us to drive otherwise thermodynamically unfavorable reactions. ${ }^{14-16}$ Therefore, the assembly of efficient semiconductor-based photocatalysts capable of performing selective organic transformations represents a major chemical research goal.

Although the photocatalytic fine chemical synthesis exhibits several prominent advantages, the selectivity remains substandard. The generation of free radical intermediates during the photocatalytic redox processes is detrimental to reach the desired selectivity. ${ }^{10}$ This issue becomes especially critical for selective oxidizing organic reactants using molecular oxygen since its reaction with free radical intermediates (e.g., superoxide radicals) often results in uncontrolled oxidation products. ${ }^{11}$ Fortunately, by selecting appropriate photocatalysts and mastering the reaction conditions, the synthetic pathways for fine chemical synthesis can be controlled with the desired selectivity toward target organic products. ${ }^{17}$ Furthermore, various sacrificial reagents to speed up the elimination of photogenerated holes are generally required for the photocatalytic reduction reactions. Such reagents reduce the applicability of the systems due to an increased cost and also waste the energy of holes for practical organic transformations. ${ }^{18-21}$ Where most photocatalytic organic transformation systems only focus on selective reductions or oxidations, the environmental and economic benefits of a dual-functional photocatalytic process would be significant for a wide range of selective organic conversions.

Recently, dual-functional photocatalytic reaction systems composed of coupled selective organic reduction and oxidation reactions have received extensive attention due to the efficient utilization of both photogenerated electrons and holes to produce value-added organic products. ${ }^{4,22-25}$ For instance, Dai et al. have reported a coupled system where the selective oxidation of aromatic alcohols to aldehydes is combined with the reduction of nitrobenzene to aniline. ${ }^{26}$ Since the photoexcited electrons and holes react directly with the organic reactants, avoiding the formation of highly reactive radical intermediates, such a coupled system exhibits a high selectivity toward target products. ${ }^{27-29}$ Moreover, combining selective organic oxidation with chemical fuel generation (e.g., $\mathrm{H}_{2}, \mathrm{CO}$ ) can further maximize the added value offered by dual-functional photocatalytic systems. ${ }^{30}$ Despite that, the dual-functional photo(electro)catalytic $\mathrm{H}_{2}$ generation with the degradation of organic pollutants has recently been reviewed, ${ }^{31,32}$ a summary of the research efforts related to dual-functional photocatalysts toward selective organic transformation is still lacking.

In this review, the dual-functional photocatalytic selective organic transformations to produce various valuable chemical products are introduced, which have been divided into two classes hinging on the different redox reaction processes. Both types embrace organics' selective oxidation coupled with either particular organic reduction reactions or fuel generation (e.g., $\mathrm{H}_{2}, \mathrm{CO}, \mathrm{CH}_{4}$, methanol). Moreover, a personal perspective for developing dual-functional reaction systems in the future has also been proposed. 
This review provides practical information on the basic principles and mechanisms of dual-functional photocatalysis and aims to offer guidelines for the development of next-generation photocatalytic selective organic transformation systems.

\section{Fundamental principles of photocatalysis for organic synthesis}

\subsection{Traditional photocatalytic systems for selective organic transformation}

Based on the energy band theory, ${ }^{33-35}$ the fundamental mechanism of photocatalytic organic transformations by solid semiconductor photocatalysts is summarized: (1) semiconductor can capture light to generate electrons at the conduction band (CB) and holes in the valence band (VB); (2) the photogenerated charge carriers are separated and transferred to the photocatalysts surface; (3) the photoexcited electrons drive the reduction reactions, and the holes perform the oxidation reactions. The overall kinetics and thermodynamic equilibrium of these three distinct steps define the material's photocatalytic activity. ${ }^{32}$ Notably, most photocatalytic organic transformation systems do not employ the full economic potential of the photogenerated charges since only solely reduction (or oxidation) products are produced. Moreover, the use of various sacrificial reagents to improve the reaction selectivity and product yield raises the cost of the system and wastes part of the potential of the generated charge carriers, leading to processes with limited practical applicability.

\subsection{Dual-functional photocatalytic system for value-added organic transformation}

Compared to common photocatalytic reaction systems, a dual-functional photocatalytic system could simultaneously drive the reduction and oxidation reactions using photogenerated electrons and holes, respectively, to generate value-added products. ${ }^{4,22,23,31,32}$ Figure 1 shows the overall reaction mechanism of dual-functional photocatalysis. Under the irradiation of light, the electrons are excited to the CB of the semiconductor, leaving holes in the VB (Process 1). Next, the photogenerated charge carriers could transfer to the surface of semiconductor (Process 2), where both the reduction and/or oxidation reactions could occur independently, as illustrated in Process 3 and 4. Moreover, the as-formed reduction product $\mathrm{Re}_{1}$ and oxidation product $\mathrm{Ox}_{2}$ may further combine via a subsequent coupling reaction to produce new organic chemicals by controlling the reaction conditions (Process 5).

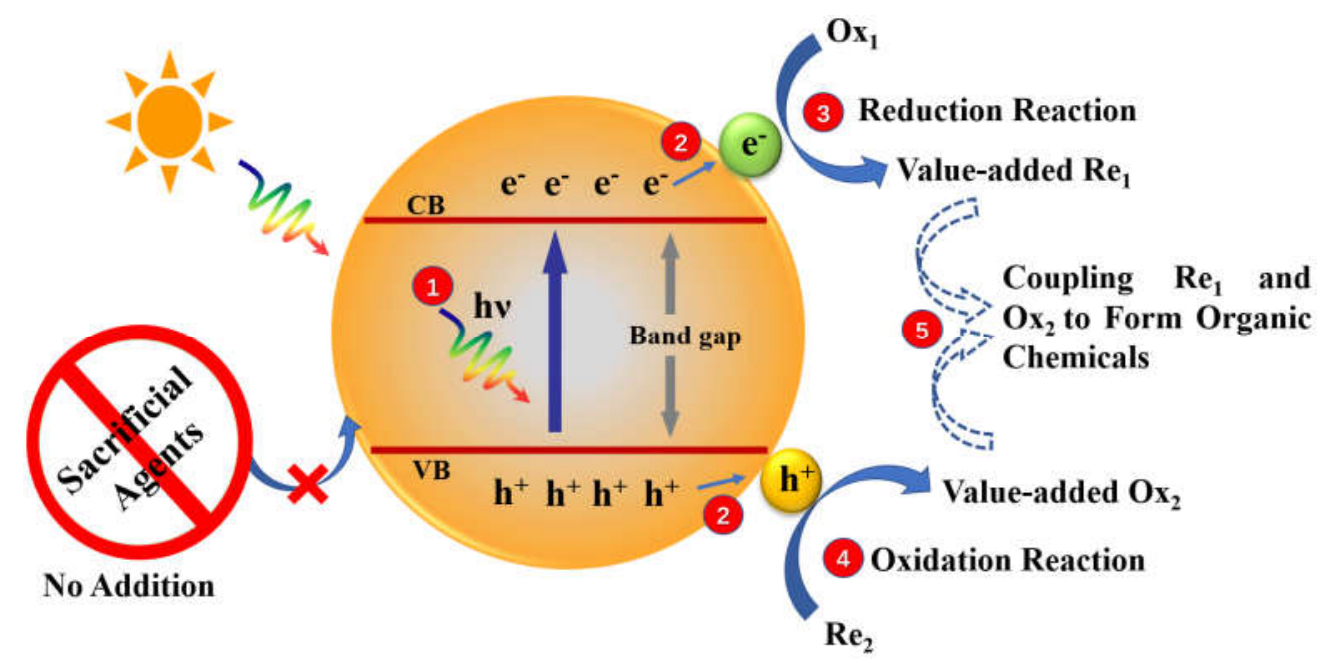

Figure 1. Fundamental principles of dual-functional photocatalysis for the generation of value-added organics $\left(\mathrm{Re}_{1}\right.$ and $\left.\mathrm{Ox}_{2}\right)$ from chemical starting compounds $\left(\mathrm{Ox}_{1}\right.$ and $\left.\mathrm{Re}_{2}\right)$ using the energy from absorbed photons (hv). Process 1: Photogenerated electrons and holes pairs; Process 2: Migration of electrons and holes; Process 3: Reduction reaction; Process 4: Oxidation reaction; Process 5: Coupling reaction between 
$\mathrm{Re}_{1}$ and $\mathrm{Ox}_{2}$.

\subsection{General principles for designing efficient dual-functional photocatalytic systems toward value-added organic transformation}

The general principles for the establishment of efficient dual-functional photocatalytic systems toward value-added organic transformation are introduced. Firstly, a suitable semiconductor material is of significant importance. Generally, semiconductor materials with relatively small bandgaps can make full use of light, thus enhancing the utilization of solar energy. ${ }^{21,36}$ However, the bandgap of semiconductor should not be too small since the material with a small bandgap will inevitably lead to the decrease of CB potential and/or the reduction of VB potential, which indicates the weakened reduction and oxidation capabilities. When the reactants have a higher redox potential, it will out of the redox ability of photocatalysts, and the reaction will not occur. Therefore, the selection and application of photocatalytic materials for dual-functional organic transformation should take these two aspects into account.

Secondly, the photocatalytic efficiency of the dual-functional reaction systems is demonstrated to be determined by the spatial separation of photoexcited electron-hole pairs. To achieve this goal, various strategies have been proposed, including doping, metal loading, and/or heterojunctions construction. By doping the semiconductor, the bandgap can be regulated and the carrier mobility can be tuned, thus facilitating the dual-functional reactions. ${ }^{37,} 38$ Metal nanoparticles supported on the photocatalyst surface can also effectively improve its catalytic performance. For example, $\mathrm{Pt}, \mathrm{Pb}, \mathrm{Au}, \mathrm{Ag}$ and $\mathrm{Rh}$ nanoparticles act as electron mediators, accelerate the rapid transfer of charge carriers, and provide active sites for oxidation and/or reduction reactions, thus enhancing the photoactivity of the catalysts toward organic transformation. ${ }^{23,39-41}$ Additionally, the development of abundant non-noble metals as alternatives materials is highly suggested to reduce the cost of dual-functional photocatalysts. Constructing semiconductor heterostructures is also an effective way to promote photocatalytic efficiency of dual-functional reaction systems. Various heterostructures, such as p-n heterojunctions, type-II heterojunctions, Z-scheme heterojunctions and surface heterojunctions, have been reported in the literatures. ${ }^{6,17,42-44}$ The as-formed heterostructures could increase the light absorption intensity of the catalysts and greatly suppress the bulk and surface recombination events of electrons and holes as there are virtually no free charges of the opposite sign in the respective materials. ${ }^{33}$ Therefore, constructing semiconductor heterostructures has been widely reported to obtain the efficient dual-functional photocatalytic systems toward value-added organic transformation.

Thirdly, the adsorption (desorption) of the reactants (products) onto the surface of photocatalyst is the foundation step toward improving the catalytic activity for dual-functional organic transformation. The more reactants are adsorbed on the surface, the more quick reaction between the molecules and charge carriers, meanwhile, the faster the desorption of the newly formed products, the higher yield and/or selectivity of the target products. ${ }^{45}$ Since the absorption of reactants could be increased by enhancing the surface area of a photocatalyst, the semiconductor materials have been designed to expose more external surfaces by reducing the dimensions of materials into nanosize, including nanoparticles, nanorods, and nanosheets. ${ }^{39}$ Moreover, the introduction of porosity in the materials could develop the internal surface area to increase the exposed surface area. However, the small pores may also impact the mass transfer process of the products and/or reactants. Therefore, a good trade-off between the mass transfer properties and the surface area should take into consideration to achieve efficient dual-functional photocatalysts.

3. Merging selective reduction and oxidation of organic compounds in dual-functional photocatalytic systems 
The coupling of photocatalytic selective reduction and oxidation reactions in one dual-functional system is categorized into three groups based on the targeted fine chemicals. In the following sections, these different groups are systematically discussed.

\subsection{Photocatalytic nitrobenzene reduction coupled with aromatic alcohol oxidation}

The selective photocatalytic production of various amines, important intermediates for pesticides, pigments, and dyes, ${ }^{46}$ by reducing their corresponding nitrobenzenes has been extensively studied in the literatures. $^{40,47,48}$ However, most of the reports employ different hole scavengers, e.g., ethanol, triethanolamine, etc., to consume the photoexcited holes. The oxidative power of the photogenerated holes is hence not used, and stoichiometric amounts of byproducts are produced. ${ }^{49-51}$ Alternatively, the optimized dual-functional photocatalytic redox systems can couple the nitrobenzene reduction with the aromatic alcohols oxidation to make full use of the photogenerated electrons and holes, simultaneously producing two different value-added chemical products. ${ }^{26,52,53}$

For instance, Dai et al. reported the simultaneous production of aniline and aromatic aldehyde using nitrobenzene and aromatic alcohol as reactants with a visible-light-driven photocatalyst composite of $\mathrm{CdS} / \mathrm{g}-\mathrm{C}_{3} \mathrm{~N}_{4} \cdot{ }^{26}$ The photocatalytic activity and stability of $\mathrm{CdS} / \mathrm{g}-\mathrm{C}_{3} \mathrm{~N}_{4}$ composite were higher than that of pristine $\mathrm{g}-\mathrm{C}_{3} \mathrm{~N}_{4}$ or $\mathrm{CdS}$ samples. Specifically, the conversion of benzyl alcohol and nitrobenzene over the optimized $\mathrm{CdS}(10.0 \mathrm{wt} \%) / \mathrm{g}-\mathrm{C}_{3} \mathrm{~N}_{4}$ material were approximately $48.0 \%$ and $49.2 \%$, respectively, after $4 \mathrm{~h}$ visible light irradiation (Figure 2A and B). Moreover, the selective reduction of nitrobenzene could be merged with the oxidation of different alcohols (benzylic and allylic alcohols). Figure 2C shows the proposed reaction mechanism for photocatalytic selective nitrobenzene reduction and alcohols oxidation. Both CdS and $\mathrm{g}-\mathrm{C}_{3} \mathrm{~N}_{4}$ semiconductors can generate electron-hole pairs by the illumination of visible light. Then, the electron will directly transfer from the $\mathrm{CB}$ of $\mathrm{g}-\mathrm{C}_{3} \mathrm{~N}_{4}$ to that of $\mathrm{CdS}$, while the holes will spontaneously move from the VB of CdS to that of $\mathrm{g}-\mathrm{C}_{3} \mathrm{~N}_{4}$. The accumulated holes in $\mathrm{g}-\mathrm{C}_{3} \mathrm{~N}_{4}$ oxidized the aromatic alcohols by removing hydrogen atoms, while the electrons in $\mathrm{CdS}$ triggered the reduction of nitrobenzene to form the corresponding aniline in the presence of protons. However, the selectivity of aniline in the coupled system was still moderate $(<60 \%)$. Moreover, the experimental evidence for the proposed mechanism was not provided. Therefore, future research efforts should be paid to understand the underlying mechanisms of the coupled photocatalytic reaction systems and rationally improve the overall process selectivity.
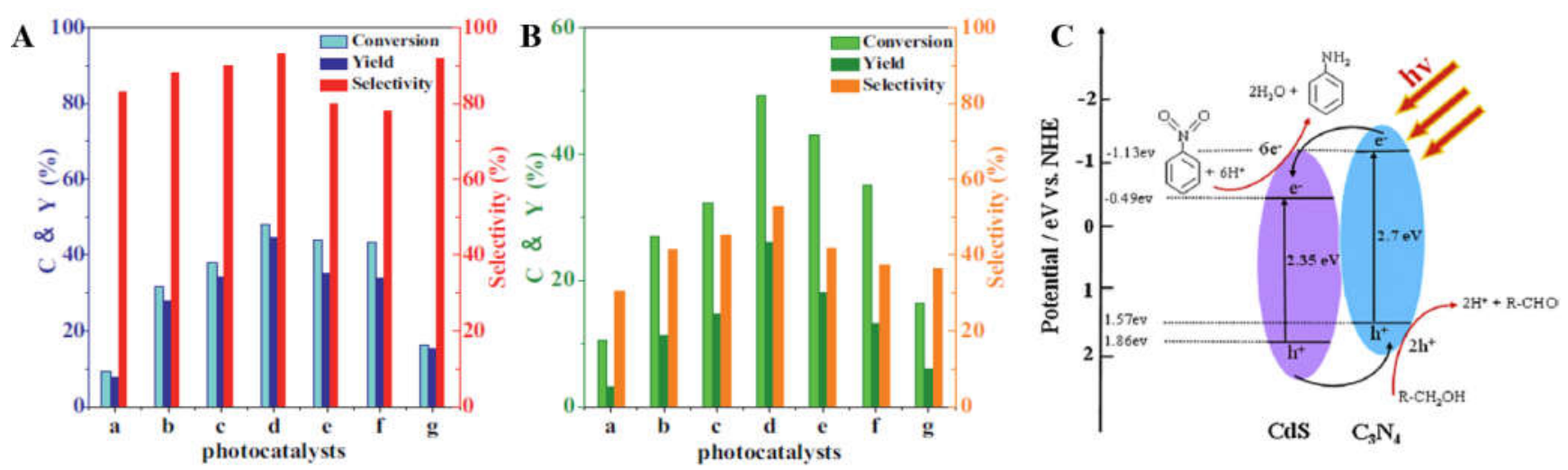

Figure 2. Performance of the (a) g- $\mathrm{C}_{3} \mathrm{~N}_{4}$, (b) $\mathrm{CdS}\left(1.0\right.$ wt.\%)/g- $\mathrm{C}_{3} \mathrm{~N}_{4}$, (c) $\mathrm{CdS}(5.0 \mathrm{wt} . \%) / \mathrm{g}-\mathrm{C}_{3} \mathrm{~N}_{4}$, (d) $\mathrm{CdS}$ (10.0 wt.\%)/g- $\mathrm{C}_{3} \mathrm{~N}_{4}$, (e) $\mathrm{CdS}\left(15.0\right.$ wt.\%)/g- $\mathrm{C}_{3} \mathrm{~N}_{4}$, (f) $\mathrm{CdS}\left(20.0\right.$ wt.\%)/g- $\mathrm{C}_{3} \mathrm{~N}_{4},(\mathrm{~g}) \mathrm{CdS}$ samples for selective oxidation of benzyl alcohols to benzaldehyde (A) and reduction of nitrobenzene into aniline under visible light irradiation $(\lambda>420 \mathrm{~nm})$ for $4 \mathrm{~h}$ in $\mathrm{N}_{2}$ atmosphere (B). Possible mechanism of selective alcohols oxidation and nitrobenzene reduction $(\mathrm{C})$. Reproduced from $\mathrm{Ref}^{26}$. Copyright 2014 permission from 
Elsevier.

Similarly, $\mathrm{CdLa}_{2} \mathrm{~S}_{4}$ photocatalyst was used for oxidizing p-methoxybenzyl alcohol (p-MBA) to pmethoxybenzaldehyde (p-MBAD) and reducing nitrobenzene (NB) to aniline (AL) and nitrosobenzene (NSB) under the irradiation of visible light $(\lambda>420 \mathrm{~nm})$ with $\mathrm{N}_{2}$ purge condition. ${ }^{52}$ The conversion of NB and the yields for AL and NSB were $c a .96 \%, 47 \%$, and $41 \%$, respectively. While the yield of p-MBAD was around $69 \%$ with a selectivity of $96 \%$ and the conversion of p-MBA was around $71 \%$. Table 1 showed the conversion of different $\mathrm{p}$-substituted nitroarenes and aromatic alcohols over the $\mathrm{CdLa}_{2} \mathrm{~S}_{4} \mathrm{sample}$. The presence of electro-donating substituent (e.g., $\left.-\mathrm{OCH}_{3}\right)$ was beneficial for improving the selective oxidation reactions as compared with the reactants with electron-withdrawing groups (e.g., -F, and -Cl). As for the reduction reaction, the electron-withdrawing substituents were detrimental for the conversion efficiency. To investigate the underlying mechanisms of the oxidation and reduction reactions, $\mathrm{CCl}_{4}$ and triethanolamine (TEOA) were used as scavengers to capture photoexcited electrons and holes, respectively. Also, various control experiments have been performed to analyze the potential active species involved in the organic transformations. As shown in Figure 3A, when the electron scavenger of $\mathrm{CCl}_{4}$ was added into the reaction system, the conversion efficiency of NB reduced from $96 \%$ to $79 \%$ with a low selectivity of $65 \%$. The yields of AL and NSB decreased from $41 \%$ and $47 \%$ to $25 \%$ and $27 \%$, respectively. Meanwhile, as shown in Figure 3B, the performance of oxidation was slightly improved in the presence of electron scavengers. When TEOA was added into the reaction solution, the conversion of $\mathrm{p}$-MBA decreased from $73 \%$ to $42 \%$ and the yield of p-MBAD reduced from $73 \%$ to $37 \%$, indicating the critical role of holes to drive the oxidation reactions.

The photocatalytic reaction mechanism for this coupling system was proposed, as shown in Figure 3C. Under visible light illumination, the electron-hole pairs were generated in the semiconductor $\mathrm{CdLa}_{2} \mathrm{~S}_{4}$. Then, the holes oxidized the $-\mathrm{CH}_{2}(\mathrm{OH})$ to $-\mathrm{CHO}$ together with a continuous deprotonation process (process a, Figure 3C). The further oxidation of $-\mathrm{CHO}$ to $-\mathrm{COOH}$ was forbidden due to the low $\mathrm{E}_{\mathrm{vb}}$ of the $\mathrm{CdLa}_{2} \mathrm{~S}_{4}$. Two holes were required for oxidizing one alcohol group to the aldehyde, while two protons were generated at the same time. Next, these protons reacted with the nitro group to produce nitroso, hydroxylamine, and amine compounds through two, four, and six electron reduction processes (process b, Figure 3C). Moreover, the selective reduction of NB to AL and oxidation of p-MBA to p-MBAD in one reaction system were also reported by Ning et al. ${ }^{53}$ and Ling et al.,${ }^{54}$ demonstrating the feasibility of such designed photocatalytic redox systems to simultaneously utilize the photogenerated electron and hole for organic transformations. Generally, the presence of aldehydes and amines in one reactor leads to the formation of Schiff bases through the amide condensation reaction. Schiff bases are important chemicals in the fabrication of pharmaceuticals; ${ }^{55,56}$ however they were not generated or detected in these works mentioned above. 

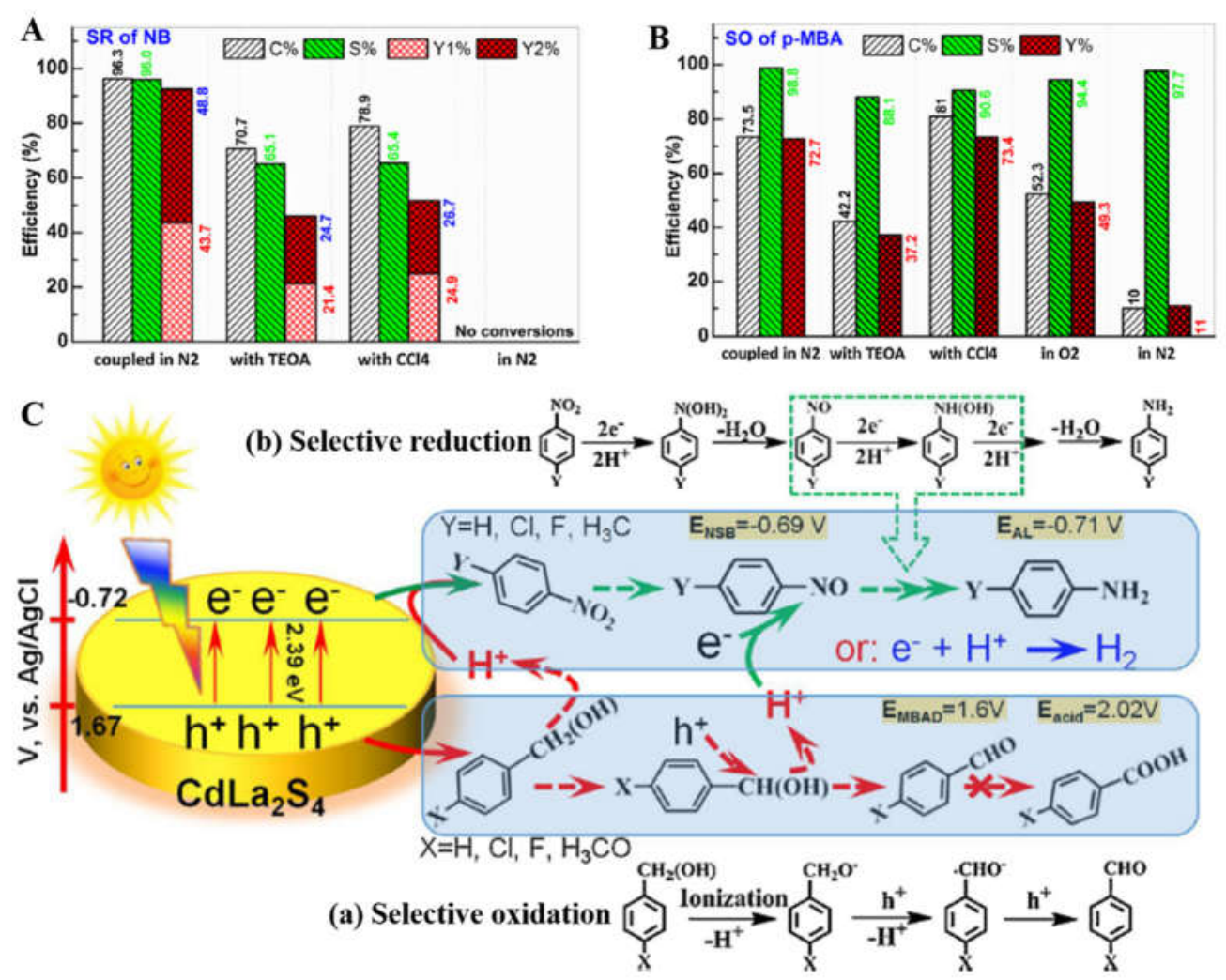

Figure 3 The photocatalytic selective reduction (SR) of NB (A) and selective oxidation (SO) of p-MBA (B) over $\mathrm{CdLa}_{2} \mathrm{~S}_{4}$ catalyst in a dual-functional reaction system with different reaction conditions. Coupling mechanism for selective oxidation of aromatic alcohols and selective reduction of nitroarenes on $\mathrm{CdLa}_{2} \mathrm{~S}_{4}$ photocatalyst (C). Reproduced from Ref ${ }^{52}$. Copyright 2018 permission from Elsevier.

Table 1 Photocatalytic conversion of other p-substituted aromatic alcohols and nitroarenes under visible light irradiation $(\lambda>420 \mathrm{~nm})$ for $4 \mathrm{~h}$

\begin{tabular}{|c|c|c|c|c|c|c|c|c|c|c|}
\hline \multirow{2}{*}{ Entry } & \multirow{2}{*}{$X-$} & \multirow{2}{*}{ Y- } & \multicolumn{3}{|c|}{ selective oxidation reactions } & \multicolumn{4}{|c|}{ selective reduction reactions } & \multirow[t]{2}{*}{$\mathrm{R}_{\mathrm{h}+\mathrm{e}-}$} \\
\hline & & & $\mathrm{C} \%$ & $\mathrm{~S} \%$ & $\mathrm{Y} \%$ & $\mathrm{C} \%$ & $\mathrm{~S} \%{ }^{\mathrm{a}}$ & $\mathrm{Y}_{1} \% \mathrm{o}^{\mathrm{b}}$ & $\mathrm{Y}_{2} \%{ }^{\mathrm{c}}$ & \\
\hline 1 & $\mathrm{H}_{3} \mathrm{CO}-$ & H- & 73.5 & 98.8 & 72.7 & 96.3 & 96.1 & 43.7 & 48.8 & $1.15: 1$ \\
\hline 2 & H- & $\mathrm{H}-$ & 62.4 & 92.5 & 57.7 & 79.8 & 32.6 & 10.2 & 15.8 & $3.01: 1$ \\
\hline 3 & $\mathrm{Cl}-$ & H- & 61.1 & 90.8 & 55.5 & 75.2 & 31.8 & 10.0 & 13.9 & $3.22: 1$ \\
\hline 4 & F- & H- & 51.9 & 90.3 & 46.8 & 73.8 & 28.2 & 9.8 & 11.0 & $3.30: 1$ \\
\hline 5 & $\mathrm{H}_{3} \mathrm{CO}-$ & $\mathrm{Cl}-$ & 61.4 & 90.9 & 55.8 & 90.2 & 30.6 & 8.7 & 18.9 & $2.56: 1$ \\
\hline 6 & $\mathrm{H}_{3} \mathrm{CO}-$ & $\mathrm{H}_{3} \mathrm{C}-$ & 51.0 & 92.3 & 47.1 & 66.0 & 36.7 & 9.6 & 14.6 & $2.64: 1$ \\
\hline 7 & $\mathrm{H}_{3} \mathrm{CO}-$ & F- & 62.4 & 91.2 & 56.9 & 90.5 & 33.7 & 10.2 & 20.3 & $2.40: 1$ \\
\hline 8 & H- & $\mathrm{H}_{3} \mathrm{C}-$ & 52.9 & 86.4 & 45.7 & 64.9 & 30.9 & 6.7 & 13.4 & 2.92:1 \\
\hline 9 & $\mathrm{Cl}-$ & F- & 60.9 & 91.6 & 55.8 & 78.2 & 23.4 & 5.8 & 12.5 & $3.86: 1$ \\
\hline 10 & F- & $\mathrm{Cl}-$ & 56.0 & 89.6 & 50.2 & 76.8 & 35.7 & 10.5 & 16.9 & $2.46: 1$ \\
\hline 11 & H- & $\mathrm{Cl}-$ & 62.5 & 93.9 & 58.7 & 80.3 & 36.9 & 10.9 & 18.7 & $2.63: 1$ \\
\hline $12^{\mathrm{d}}$ & $\mathrm{H}_{3} \mathrm{CO}-$ & $\mathrm{H}-$ & 61.0 & 80.3 & 48.9 & 75.3 & 15.2 & - & 11.4 & 4.29:1 \\
\hline $13^{\mathrm{e}}$ & $\mathrm{H}_{3} \mathrm{CO}-$ & $\mathrm{H}-$ & 61.0 & 90.3 & 55.0 & 75.3 & 39.5 & - & 29.7 & $1.85: 1$ \\
\hline
\end{tabular}

${ }^{a}$ Estimated based on nitroso and aniline compounds. ${ }^{\mathrm{b}}$ Yields of the nitroso compounds. ${ }^{\mathrm{c}}$ Yields of the 
amines. ${ }^{\mathrm{d}}$ Test performed on CdS nanorods. ${ }^{\mathrm{e}}$ Test performed on CdS nanorods, and the product of Schiff base was taken into the calculations. Reproduced from Ref ${ }^{52}$. Copyright 2018 permission from Elsevier.

Recently, Zhang and co-workers fabricated CdS nanorods modified with the ultra-low amounts (0.03\%) of $\mathrm{Pt}$ nanoparticles $(\mathrm{Pt} / \mathrm{CdS})$ composite for the selective reduction of $\mathrm{NB}$ to AL and oxidation of $\mathrm{p}-\mathrm{MBA}$ to p-MBAD in one reaction system. ${ }^{41}$ Notably, the as-formed p-MBAD partially reacted with AL to generate Schiff base compounds, which have seen widespread applications in pharmacy science and the chemical industry. The production of Schiff base can be attributed to the nucleophilic addition reaction between the as-formed aromatic aldehyde and aromatic amine. Specifically, the nucleophile is the aromatic amine and a lone electron pair in the $\mathrm{N}$ atom could attack the carbon atom with positive charge in the carbonyl group. The $\alpha$-hydroxylamine compound as a reaction intermediate will be produced via the nucleophilic addition reaction, which could dehydrate to form the final product of Schiff base. The formation of Schiff base was also detected by Higashimoto's group ${ }^{57}$ using $\mathrm{CdS}-\mathrm{TiO}_{2}$ as photocatalysts with nitrobenzene and benzyl alcohol as raw materials under the illumination of visible light $(\lambda>420 \mathrm{~nm})$. The Schiff base produced on the surface of catalyst by the condensation reaction between benzaldehyde and aniline even under dark conditions. However, the yield of the Schiff base was rather low. Later work by the same group showed the importance of the solvent on the one-pot synthesis of Schiff bases. ${ }^{58}$ Non-polar solvents (cyclohexane, toluene) were more favorable for the synthesis of Schiff base than the polar solvents (acetonitrile, ethanol, water). Specifically, the yield of Schiff base was $99 \%, 44 \%, 9 \%$, and 0 in cyclohexane, acetonitrile, ethanol, and water, respectively, over the $\mathrm{TiO}_{2} / \mathrm{CdS}$ photocatalyst under the illumination of visible light $(\lambda>420$ $\mathrm{nm})$.

Wu et al. directly produced the Schiff base by combining nitrobenzene and benzyl alcohol using a series of $\mathrm{Cdx}_{\mathrm{X}} \mathrm{Zn}_{1-\mathrm{XS}}(0 \leq \mathrm{X} \leq 1)$ samples under the irradiation of visible light $(\lambda>420 \mathrm{~nm}) .{ }^{59}$ The $\mathrm{Cd}_{0.78} \mathrm{Zn}_{0.22} \mathrm{~S}$ exhibited the highest yield of Schiff base (55\%) after 4 hours reaction. Importantly, the yield of Schiff base influenced by the substituents on the aromatic alcohol. Specifically, the aromatic alcohols with electron-donating groups $\left(-\mathrm{OCH}_{3},-\mathrm{CH}_{3}\right)$ produced more Schiff base products than those with electronwithdrawing groups $(-\mathrm{Cl},-\mathrm{F})$. Moreover, using orthochloro-substituted benzyl alcohol as reactant was favorable for forming Schiff base as compared with para- and metachloro-substituted benzyl alcohol due to the effect of steric effects. Notably, the selectivity of Schiff base was still low in this reaction system. Therefore, producing a Schiff base with high selectivity in the dual-functional reaction system would be desirable. Recently, Yang and co-workers ${ }^{60}$ demonstrated a dual-functional reaction system for directly converting benzyl alcohol and nitrobenzene into Schiff base using $\mathrm{TiO}_{2}$ microspheres as photocatalysts under light irradiation $(380<\lambda<760 \mathrm{~nm})$. After $3 \mathrm{~h}$ light illumination, Schiff base was the only product in the system with selectivity of $100 \%$. The photoactivity of $\mathrm{TiO}_{2}$ microspheres was well maintained after five cycles, indicating the good recyclability of $\mathrm{TiO}_{2}$ microspheres. A comparative summary of nitrobenzene reduction reaction coupled with aromatic alcohols oxidation is listed in Table S1 (Supporting Information).

Despite numerous works for coupling the photocatalytic nitrobenzene reduction with aromatic alcohol oxidation, the reported photocatalysts are mainly focus on the metal sulfides. It is well-known that the metal sulfide-based photocatalysts suffer from the light-induced decomposition, i.e., photocorrosion, which may inhibit their further large-scale implementations. Therefore, developing different stable photocatalysts for long-time photocatalytic nitrobenzene reduction coupled with aromatic alcohol oxidation is critical for technological applications. Moreover, the underlying reaction mechanism for coupling the photocatalytic nitrobenzene reduction with aromatic alcohol oxidation should be further clarified. For instance, the understanding on the formation of Schiff bases due to the amide condensation reaction between aldehydes and amines are insufficient and the efficient methodologies to control the production of Schiff bases is still lacking. Therefore, the insight into the precondition and discipline of Schiff bases formation is of significant 
importance for understanding the photocatalytic reaction mechanism toward the coupling of nitrobenzene reduction with aromatic alcohol oxidation.

\subsection{Photocatalytic C-C cross-coupling reactions}

The C-C cross-coupling reaction is an attractive research area in modern synthetic organic chemistry. ${ }^{61-}$ ${ }^{63}$ However, for the traditional thermal $\mathrm{C}-\mathrm{C}$ coupling reactions, high temperatures are generally required to climb the activation energy barrier for triggering the electron transfer and redox process. ${ }^{64}$ Nevertheless, the high reaction temperature may lead to the formation of various unwanted byproducts. ${ }^{65}$ Recently, photocatalytic $\mathrm{C}-\mathrm{C}$ bond formation using light energy attracts much attention due to the possibility to form fuel in a clean way with minimized environmental impact. ${ }^{64,66-73}$ Different kinds of well-known C-C crosscoupling reactions (Suzuki, Hiyama, Stille, Sonogashira, and Heck) and condensation reactions (Mannich, Diels-Alder, AzaHenry, oxidative cyanation, etc.) can be performed under light irradiation. ${ }^{64,74-79}$ During the $\mathrm{C}-\mathrm{C}$ cross-coupling reaction, both the photogenerated electrons and holes are fully utilized, which represents an efficient dual-functional photocatalytic system.

Jiao and co-workers prepared a $\mathrm{Pd}$ nanoparticle (NP) modified $\mathrm{SiC}$ photocatalyst $(\mathrm{Pd} / \mathrm{SiC})$ for catalyzing the $\mathrm{C}-\mathrm{C}$ coupling of phenylboronic acid with iodobenzene (Suzuki-Miyaura reaction) under the illumination of visible light $(\lambda>400 \mathrm{~nm}) .{ }^{44} \mathrm{The} \mathrm{Pd} / \mathrm{SiC}$ composite showed excellent photoactivity toward iodobenzene conversion (99\%) with a TOF of $1053 \mathrm{~h}^{-1}$. Moreover, the coupling of a series of substituted phenylboronic acid and iodobenzenes over $\mathrm{Pd} / \mathrm{SiC}$ photocatalyst was demonstrated, which suggests its generality toward Suzuki-Miyaura reactions. As shown in Table 2, iodobenzenes with electron-donating substitutions (entries 4-6) exhibited lower photoactivity than those with electron-withdrawing substitutions (entries 1-3). Similar conversion and selectivity were observed for coupling iodobenzene with various phenylboronic acids (entries 7-9). With bromobenzene derivatives and phenylboronic acids, more than $90 \%$ of the bromobenzenes with different derivatives converted after $5 \mathrm{~h}$ reaction (entries 10-11). However, the photocatalytic selectivity of $\mathrm{Pd} / \mathrm{SiC}$ was relatively low. The recyclability of $\mathrm{Pd} / \mathrm{SiC}$ photocatalyst in Figure 4A demonstrated the stable activity during the recycle processes, suggesting the high stability of $\mathrm{Pd} / \mathrm{SiC}$ sample. A possible reaction mechanism toward Suzuki-Miyaura reaction was proposed (Figure 4B). The electron-hole pairs were formed in $\mathrm{SiC}$ upon light illumination, and the photoexcited electrons flowed toward the Pd NPs. The iodobenzene could be activated by the electron-rich Pd NPs to form Pd adsorbed aryl. Simultaneously, by acquiring an $\mathrm{OH}^{-}$from reaction medium, the phenylboronic acid transformed into the negative $-\mathrm{B}(\mathrm{OH})^{3-}$ species. Then, the $\mathrm{C}-\mathrm{B}$ bond in molecules of phenylboronic acid was cleaved by the photogenerated holes from SiC. Finally, the final products can be achieved via the coupling of these two redox-activated species on Pd NPs surface.
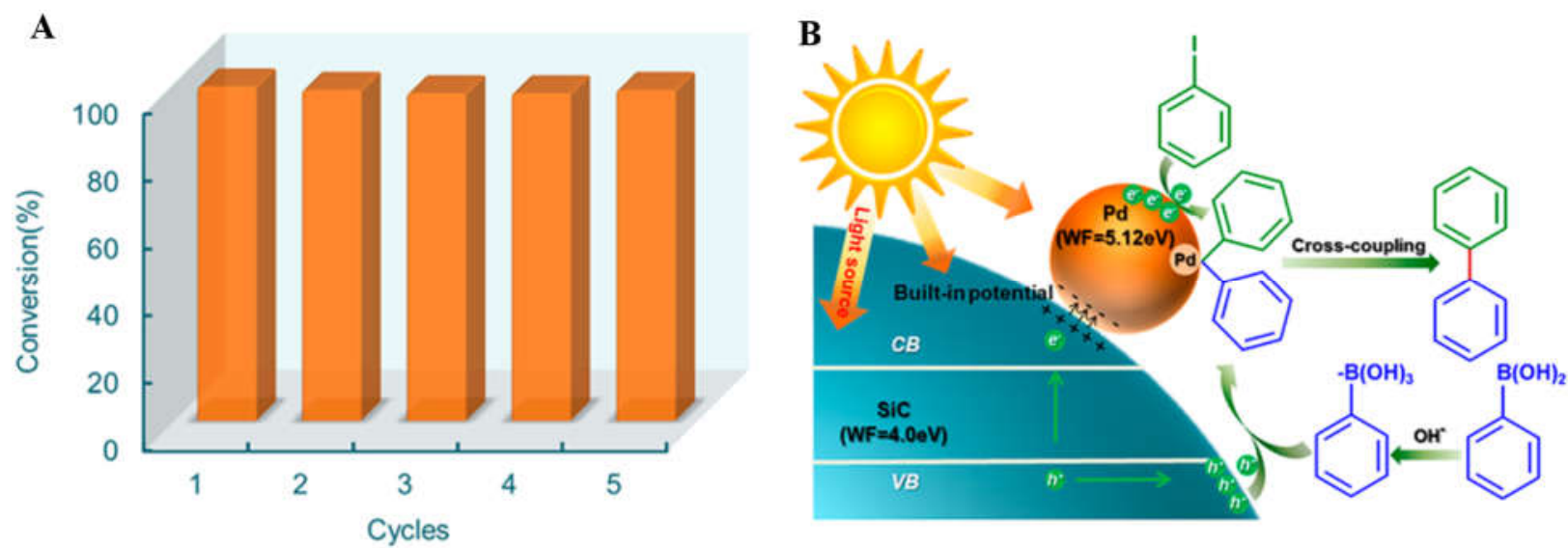

Figure 4 Recycling Suzuki-Miyaura coupling reaction over 3\% $\mathrm{Pd} / \mathrm{SiC}$ photocatalyst (A); the proposed 
mechanism for the Suzuki-Miyaura coupling reaction over $\mathrm{Pd} / \mathrm{SiC}$ sample (B). Reproduced from $\mathrm{Ref}^{44}$. Copyright 2015 permission from the American Chemical Society.

Table 2. Photocatalytic performances of $\mathrm{Pd} / \mathrm{SiC}$ for the Suzuki-Miyaura coupling reaction of aryl halides with phenylboronic acids ${ }^{a}$

(O)

${ }^{a}$ Reaction conditions: $10 \mathrm{mg}$ of $3 \% \mathrm{Pd} / \mathrm{SiC}$ catalyst, $8 \mathrm{mmol}$ of phenylboronic acid, $4 \mathrm{mmol}$ of iodobenzene or one of its derivatives, $3.91 \mathrm{~g}$ of $\mathrm{Cs}_{2} \mathrm{CO}_{3}(12 \mathrm{mmol}), 3 \mathrm{~mL}$ water, and $9 \mathrm{~mL}$ DMF. The reaction time is 80 min at the temperature of $30{ }^{\circ} \mathrm{C}$ with irradiation intensity of $0.35 \mathrm{~W} / \mathrm{cm}^{2} .{ }^{b}$ The reaction time is prolonged to $5 \mathrm{~h}$ and the other conditions are the same as in footnote a. ${ }^{c}$ The other products are the debromination products of bromobenzene derivatives. Reproduced from $\operatorname{Ref}^{44}$. Copyright 2015 permission from the American Chemical Society.

In addition to Suzuki-Miyaura reaction, the SiC-supported Pd composite also exhibited high photoactivity toward the Sonogashira reaction under the illumination of visible light. ${ }^{80}$ However, for this reaction, an elevated reaction temperature $\left(120^{\circ} \mathrm{C}\right)$ was needed. Notably, the PdCu alloy NPs decorated $\mathrm{SiC}$ composite was prepared by Wang et al. toward $\mathrm{C}-\mathrm{C}$ cross-coupling of the iodobenzene with phenylacetylene. ${ }^{81}$ The coupling reaction could react over the $\mathrm{SiC}-\mathrm{PdCu}$ composite at $60{ }^{\circ} \mathrm{C}$. The optimized $\mathrm{SiC}-\mathrm{Pd}_{3} \mathrm{Cu}_{1}$ photocatalysts, where the $\mathrm{Pd} / \mathrm{Cu}$ ratio was $3: 1$, showed higher iodobenzene conversion efficiency $(99.7 \%)$ than the SiC-Pd composite (28.6\%).

Besides inorganic photocatalysts, various polymeric materials have also been employed for C-C 
coupling reactions. ${ }^{82-85}$ For instance, a polydopamine (PDA) nanofilm with broad light absorption was reported for coupling phenylboronic acid and aryl iodides under white light irradiation at room temperature. ${ }^{82}$ In another work, Wang and co-workers immobilized Pd NPs on the support of a conjugated microporous poly(benzoxadiazole) network $\left(\mathrm{B}-\mathrm{BO}_{3}\right)$, resulting in $\mathrm{Pd} @ \mathrm{~B}-\mathrm{BO}_{3}$ hybrid photocatalysts. ${ }^{83}$ The photocatalytic Suzuki cross-coupling of iodobenzene and phenylboronic acid over $\mathrm{Pd} @ \mathrm{~B}-\mathrm{BO}_{3}$ composite reached $98 \%$ after 2 hours reaction under the illumination of visible light. The mechanism of the C-C crosscoupling reaction was similar with the above one, as shown in Figure 4. The Suzuki coupling of iodobenzene and benzeneboronic acid has also been achieved over the Pd NPs modified g- $\mathrm{C}_{3} \mathrm{~N}_{4}$ with high photocatalytic efficiency. ${ }^{85}$ In addition to the Suzuki coupling reaction, Filippini and co-workers ${ }^{86}$ reported the photocatalytic perfluoroalkylation of 1,3,5-trimethoxy-benzene in the presence of perfluoroalkyl iodides as the radical sources over the diversely modified $\mathrm{CN}$ catalysts under mild operative conditions. The thermal amorphized CN (am-CN) catalyst exhibited the highest yield (99\%) after $24 \mathrm{~h}$ reaction by normalizing the mass of photocatalyst. Notably, the hydrogen reduction treated $\mathrm{CN}$ (red-CN) catalyst showed higher photocatalytic efficiency by normalizing the surface area despite the red-CN can't convert all the reagents in 24 hours. The reaction mechanism was proposed. Before light irradiation, the halogen in $\mathrm{C}_{4} \mathrm{~F}_{9} \mathrm{I}$ could bond with the $\mathrm{N}$ atoms of $\mathrm{CN}$, which could facilitate the transfer of photogenerated electrons from $\mathrm{CN}$ to the $\mathrm{C}_{4} \mathrm{~F}_{9} \mathrm{I}$ reagent, forming ${ }^{-} \mathrm{C}_{4} \mathrm{~F}_{9}$ radicals. Then, the aromatic ring of trimethoxy-benzene was attacked by the $\cdot \mathrm{C}_{4} \mathrm{~F}_{9}$ radicals to achieve the $\mathrm{C}-\mathrm{C}$ coupling with the aid of photogenerated holes. Similarly, mesoporous graphitic carbon nitride $(\mathrm{mpg}-\mathrm{CN})$ was reported to orchestrate oxidative and reductive interfacial electron transfers to two different substrates in a two- or three-component system for direct twofold carbon-hydrogen functionalization of arenes and heteroarenes. ${ }^{87} \mathrm{~A}$ comparative summary of photocatalytic C-C cross-coupling reactions is listed in Table $\mathbf{S 2}$.

For most photocatalytic C-C cross-coupling reactions (Suzuki reactions), noble metal Pd is frequently used as the cocatalysts to accept the photogenerated electrons and then trigger the coupling reaction. Notably, the metal Pd itself is a highly active thermal-catalyst for Suzuki reactions while the possible thermal effect on the over-all photocatalytic performance is generally ignored. This will undoubtable lead to the unclear reaction mechanisms. Moreover, the ethanol has been reported to serves as solvent for the photocatalytic cross-coupling reactions. It is also widely accepted that the ethanol is a well-known sacrificial agent to trap the photogenerated holes. Under such circumstance, the exact role of ethanol is confused and the function of holes in the reaction systems is still debated. Based on the about discussion, more research attention should be paid to elucidate the underlying mechanism of the $\mathrm{C}$ - $\mathrm{C}$ cross-coupling reactions, specifically for these employing metal Pd as catalysts.

\subsection{Photocatalytic disproportionation reactions of lignin}

Lignin, composed of diversely cross-linked phenolic polymers, is an abundant source of renewable aromatics. ${ }^{88}$ Numerous efforts have been reported for increasing the profitability and sustainability of biorefinery through the efficient conversion of lignin. Generally, catalytic lignin conversion requires high temperatures, which may lead to the over-oxidation of the functionalized aromatics, alcohols or alkanes products. ${ }^{89}$ Dual-functional photocatalysis is demonstrated to be an efficient strategy for producing various aromatic compounds by cleaving lignin via a two-step oxidation-reduction approach at ambient conditions. The oxidizing power of photogenerated holes should be directed to breaking the lignin's C-C bonds, while the electrons subsequently promote the partial reduction of the $\mathrm{C}-\mathrm{O}$ bonds. ${ }^{90-92}$ Thus, designing a sustainable dual-functional photocatalytic system for efficient lignin depolymerization under mild conditions is highly attractive.

Luo et al. employed visible-light-driven heterogeneous $\mathrm{ZnIn}_{2} \mathrm{~S}_{4}$ photocatalyst to convert 2-phenoxy1-phenylethanol, as a dimeric lignin $\beta$-O-4 model, into phenols and acetophenones. ${ }^{93}$ Upon visible light $(\lambda$ 
$=455 \mathrm{~nm}$ ) illumination at $50{ }^{\circ} \mathrm{C}$, the phenolic products would not proliferate into dark substances, which was favorable for the light absorption of catalyst in the deep solution. Under such circumstances, the yield of phenols was demonstrated to be $71-91 \%$ using lignin $\beta-O-4$ models as reactants. Mechanistically, a "hydrogen pool" formed on the surface of $\mathrm{ZnIn}_{2} \mathrm{~S}_{4}$ due to the dehydrogenation process of $\mathrm{C}_{\alpha} \mathrm{H}-\mathrm{OH}$ group in the lignin $\beta-\mathrm{O}-4$ linkage. Then, the "hydrogen pool" hydrogenolytically cleaved the adjacent $\mathrm{C}_{\beta}-\mathrm{O}$ bond into two monomers. However, in this proposed reaction mechanism, the exact roles of photogenerated electrons and holes were not well defined yet. Later, the same group developed a mpg- $\mathrm{C}_{3} \mathrm{~N}_{4}$ photocatalyst for the cleavage of lignin $\beta$-O-4 and $\beta$-1 linkages under blue light irradiation $(\lambda=455 \mathrm{~nm}){ }^{92}$ The mpg- $\mathrm{C}_{3} \mathrm{~N}_{4}$ sample exhibited a high photocatalytic conversion efficiency $(96 \%)$ toward transforming the lignin $\beta-O-4$ model into different organic products such as phenyl formate, benzaldehyde, and benzoic acid, with high selectivity (91\%). The $\pi-\pi$ stacking interactions between the flexible mpg- $\mathrm{C}_{3} \mathrm{~N}_{4}$ and lignin model molecules, high charge separation efficiency and large specific surface area of the catalyst collaboratively contributed to its high photocatalytic activity. Various control experiments were conducted to explore the underlying reaction mechanisms. A hypothetical reaction mechanism was proposed (Figure 5A). Upon illumination of visible light, mpg- $\mathrm{C}_{3} \mathrm{~N}_{4}$ was first excited to generate holes and electrons separately. The photogenerated holes attacked the absorbed lignin model molecule 1 to release one proton and form a $\mathrm{C}_{\beta}$-centered radical A. Combining with $\mathrm{O}_{2}$ and protons, the radical A transferred into intermediate $\mathrm{C}$. The photogenerated electrons could active the peroxide intermediates to cleave the $\mathrm{C}_{\alpha}-\mathrm{C}_{\beta}$ and $\mathrm{O}-\mathrm{O}$ bond, thus producing the major products 3 (aromatic aldehyde) and 4 (phenyl formate). Moreover, the superoxide radical anion $\mathrm{O}_{2}{ }^{--}$ also formed due to the reaction between $\mathrm{O}_{2}$ molecules and electrons, which oxidized the benzylic alcohol to the alkoxide anion, producing byproduct 2 .

Similarly, Lin et al. employed a series of $\mathrm{Zn}_{\mathrm{m}} \mathrm{In}_{2} \mathrm{~S}_{\mathrm{m}+3}(\mathrm{~m}=1-6)$ photocatalysts to break the $\beta-\mathrm{O}-4$ bond in diverse lignin model compounds under the illumination of visible light $(\lambda=400-780 \mathrm{~nm}) .{ }^{94}$ The optimized $\mathrm{Zn}_{4} \mathrm{In}_{2} \mathrm{~S}_{7}$ catalyst selectively cleaved the $\beta-\mathrm{O}-4$ bond in lignin model compounds and organosolv lignin into aromatic monomers. Specifically, the photocatalytic conversion efficiency of a model lignin compound (i.e., 2-phenoxy-1-phenylethanol) over the $\mathrm{Zn}_{4} \mathrm{In}_{2} \mathrm{~S}_{7}$ catalyst was $99 \%$ with a high yield of acetophenone $(86 \%)$ and phenol $(82 \%)$ after $4 \mathrm{~h}$ reaction. The yield of 2-phenoxy-1-phenylethanone as a byproduct was $9.6 \%$ in the reaction system. Based on control experiments, a different one-step $\mathrm{C}_{\alpha}$ radical intermediate mechanism was proposed (Figure 5B): (1) forming electrons and holes in the $\mathrm{CB}$ and $\mathrm{VB}$ of $\mathrm{Zn}_{4} \mathrm{In}_{2} \mathrm{~S}_{7}$, respectively, (2) oxidizing $\mathrm{C}_{\alpha}-\mathrm{H}$ bond to produce intermediate $\mathrm{C}_{\alpha}$ radicals, (3) cleaving $\mathrm{C}_{\beta}-\mathrm{O}$ bond by accepting electrons to form phenol and/or acetophenone. The two-step $\mathrm{C}_{\alpha}=\mathrm{O}$ intermediate pathway was a minor process for cleaving $\beta-\mathrm{O}-4$ bond. Also other photocatalysts, such as $\mathrm{CuO}_{\mathrm{x}} / \mathrm{ceria}$ anatase nanotube composites, were also employed for the depolymerization of lignin under the illumination of visible light. ${ }^{36}$ 
A

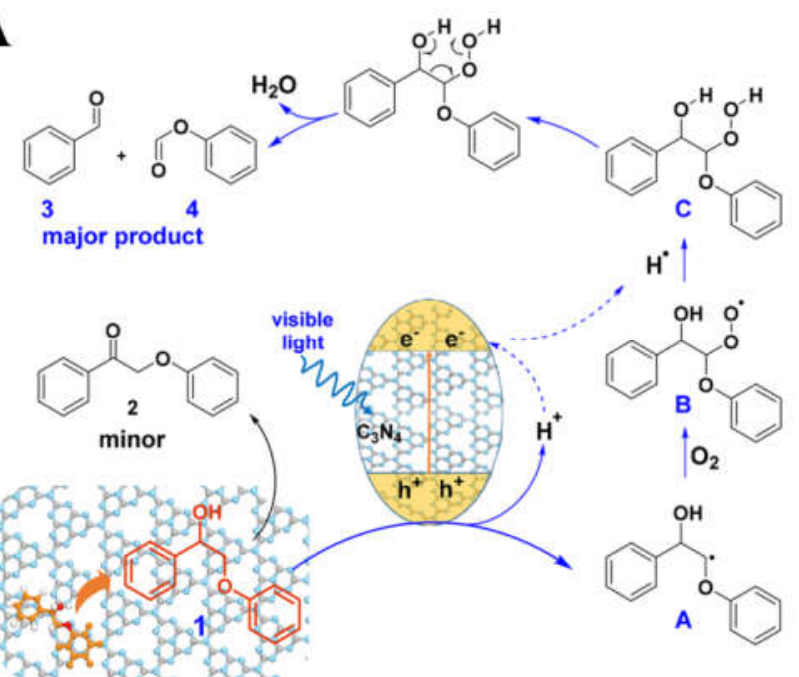

B

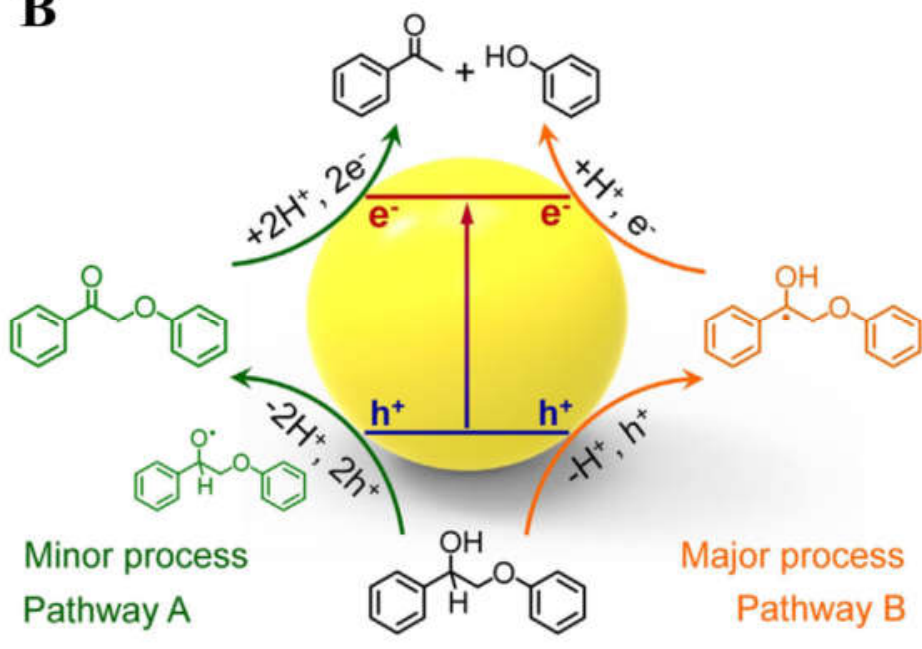

Figure 5 Proposed mechanism of mpg- $\mathrm{C}_{3} \mathrm{~N}_{4}$ catalyzed transformation of molecule 1 (A). Reproduced from Ref $^{92}$. Copyright 2018 permission from the American Chemical Society. Proposed mechanism for $\beta-\mathrm{O}-4$ bond cleavage in the photocatalytic conversion of lignin over the $\mathrm{Zn}_{4} \mathrm{In}_{2} \mathrm{~S}_{7}$ catalyst (B). Reproduced from $\mathrm{Ref}^{94}$. Copyright 2019 permission from the Wiley-VCH.

Thus far, various photocatalytic dual-functional reaction systems have been established toward lignin fraction transformation. Nevertheless, lignin model compounds are frequently employed as the reactants in the reported literatures but not the native lignin. Moreover, to increase the contact between lignin and catalyst, the high-temperature solvolysis of lignin is generally required for heterogeneous catalysis. Under such circumstances, a solubilizing catalyst method using 3-mercaptopropionic acid (MPA) capped CdS quantum dots (CdS QDs) as photocatalysts was proposed by Wu and co-workers for the depolymerization of native lignin under the illumination of visible light $(\lambda=400-780 \mathrm{~nm}) .{ }^{95}$ Theoretically, selectively cleaving the $\beta-\mathrm{O}-4$ linkages leaded to maximum yield of aromatic monomers (32\%). After photocatalytic conversion, the major products in the liquid phase were monomeric aromatics, including syringyl- and guaiacyl-derived ketones, with a total yield of $26.7 \mathrm{wt} \%$, corresponding to $84 \%$ of the theoretical maximum (Figure 6C). The lignin model compound, i.e., 2-phenoxy-1-phenylethanol (PP-ol), was employed as reactants to further reveal the underlying depolimerizaiton mechanism. In the reaction process, the conversion of PP-ol was reduced when the electron and hole scavengers were added, suggesting that the production of phenol and acetophenone were affected by both the photogenerated electrons and holes (Figure 6A (iii-v)). The reaction was also inhibited when the radical scavenger, 5,5-dimethyl-1-pyrrolineN-oxide (DMPO), was introduced, stating that the reaction was carried out through radical intermediates (Figure 6A vi). Moreover, when the benzyl hydrogen substituted by methyl, the reaction stopped completely (Figure 6 vii). Therefore, the presence of $\mathrm{C}-\mathrm{H}$ bond played a very pivotal role in the photocatalytic process. The production of possible radical intermediates on CdS surfaces by cleaving the $\mathrm{C}_{\alpha}-\mathrm{H}, \mathrm{C}_{\beta}-\mathrm{H}$, and $\mathrm{O}-\mathrm{H}$ bonds were calculated through density functional theory (DFT). It was found that the cleavage of $\mathrm{C}_{\alpha}-\mathrm{H}$ bond exhibited the least positive oxidative dehydrogenation potential (1.1 V versus SHE) (Figure 6B), which suggested that the $\mathrm{C}_{\alpha}-\mathrm{H}$ bond was firstly fractured when oxidized by holes, leading to the formation of $\mathrm{C}_{\alpha}$ radical. The $\beta-\mathrm{O}-4$ bond in the $\mathrm{C}_{\alpha}$ radical was broken in the presence of electrons, thus forming the products of acetophenone and phenoxy anion during geometry optimization. Therefore, an electron-hole-coupling mechanism was proposed based on the above experimental and computational results. Detailly, the $\mathrm{C}_{\alpha}$ radical intermediates were first formed by oxidative dehydrogenation of $\mathrm{C}_{\alpha}-\mathrm{H}$ bonds driven by holes, and then the intermediate initiated a reductive cleavage of $\beta-\mathrm{O}-4$ bonds driven by electrons. The catalyst can be repeatedly used through reversible aggregation-colloidization strategies, and the results 
showed stable yield for aromatic monomers during the five times recycles reaction, reflecting the satisfactory stability of the catalyst, as shown in Figure 6C. Moreover, a comparative summary of photocatalytic disproportionation reactions of lignin is listed in Table S3.

A

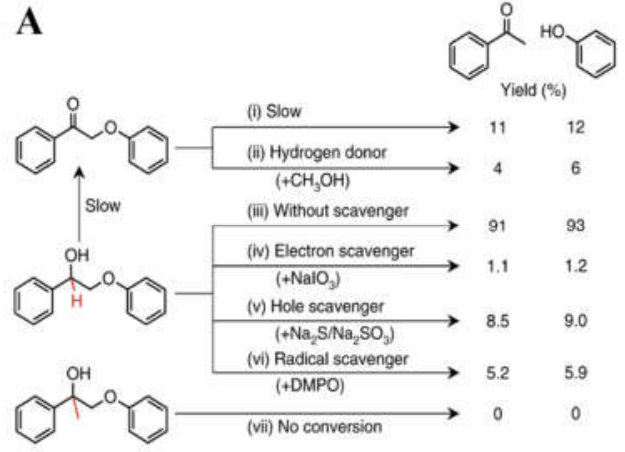

B

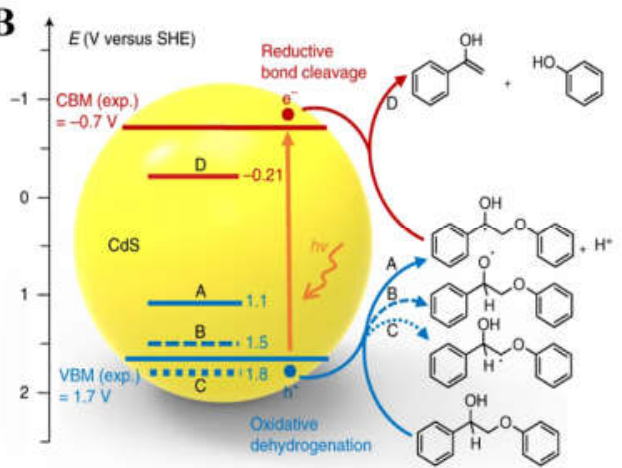

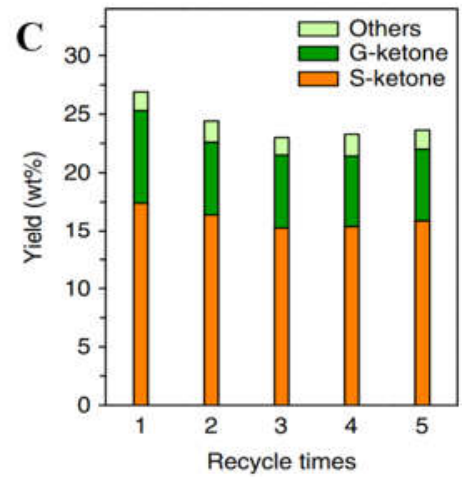

Figure 6 Control experiments under different conditions (A). Potentials of oxidative dehydrogenation of three different paths $(\mathrm{A}, \mathrm{B}, \mathrm{C})$ and potential of reductive cleavage of $\beta-\mathrm{O}-4$ bond in the $\mathrm{C}_{\alpha}$ radical intermediate (B). Repeated uses of CdS-MPA QDs (C). Reproduced from Ref ${ }^{95}$. Copyright 2018 permission from Springer Nature.

The research for photocatalytic conversion of lignin is in its infancy and there are still some questions need to be tackled. For instance, $\mathrm{Wu}$ et al. found that $\mathrm{CdS}$ nanoparticles exhibit the highest photoactivity for selective breaking the $\beta-\mathrm{O}-4$ bonds as compared with other semiconductors (such as, $\mathrm{TiO}_{2}, \mathrm{ZnS}, \mathrm{Cu}_{2} \mathrm{O}$ etc.). ${ }^{95}$ Notably, the reason why the $\beta-\mathrm{O}-4$ bonds are prone to fracture on the surface of $\mathrm{CdS}$ is unknow. A systematic study to investigate the key step for $\beta-\mathrm{O}-4$ bonds breaking is urgent to offers opportunities to develop efficient catalyst toward photocatalytic conversion of lignin. Furthermore, the understanding on the mechanism of $\beta-\mathrm{O}-4$ bonds breaking should be deepened and reinforced. Up to now, different mechanisms have been proposed to explain the breaking of $\beta-\mathrm{O}-4$ bonds, while it still lacks of strong evidences to directly trap the intermediates to validate and unify the final reaction mechanisms. At the same time, the photocatalytic efficiency of the system needs to be further improved. This contains two aspects. One is the unsatisfied formation rates of the final products and the other one is the relatively low total amounts of products after batch reactions. Therefore, to achieve large-scale applications, the design of highly efficient and stable photocatalytic reaction system towards photocatalytic conversion of lignin into value added chemical products is necessary.

\section{Merging selective organic transformations and chemical fuel generation in dual-functional photocatalytic systems}

Apart from the production of oxidized and reduced organic products simultaneously, ${ }^{31,}{ }^{32}$ combining reductive solar fuel generation (e.g., $\mathrm{H}_{2}, \mathrm{CO}$ ) with selective organic oxidation reaction has also been widely investigated in the dual-functional photocatalytic reaction systems. ${ }^{32}$ In the following sections, three different categories of dual-functional reaction systems for simultaneously selective organic oxidation and fuel generation will be introduced.

\subsection{Photocatalytic oxidation of various alcohols coupled with hydrogen evolution}

Generally, photocatalytic hydrogen generation employs various alcohols as sacrificial reagents to speed up the consumption of the photogenerated holes. Alternatively, utilizing the holes to selectively convert various alcohols into value-added products can replace the need for sacrificial reagents. ${ }^{96}$ For instance, Higashimoto and co-workers reported a $\mathrm{CdS} / \mathrm{TiO}_{2}$ photocatalyst decorated with $\mathrm{Pd} \mathrm{NPs}$ for coupling $\mathrm{H}_{2}$ production with selective oxidization of benzyl alcohol into benzaldehyde ( $99 \%$ selectivity) in water under 
the illumination of visible light. ${ }^{97} \mathrm{The} \mathrm{CdS} / \mathrm{TiO}_{2}-\mathrm{Pd}$ composite displayed an excellent productivity of 36 $\mu \mathrm{mol} \mathrm{H}_{2}$ and $48 \mu \mathrm{mol}$ benzaldehyde after 4 hours reaction. However, further mechanistic research was not performed in this work.

The same photocatalytic process with the simultaneous selective oxidation of aromatic alcohols with $\mathrm{H}_{2}$ generation was studied by Han and co-workers. ${ }^{98}$ The bimetal-semiconductor hybrids with two different architectures, including anisotropic Pt-tipped nanorods (NRs) decorated CdS (Au-Pt@CdS) and Pt-covered Au NRs decorated CdS (Au@Pt@CdS), were fabricated for photocatalytic $\mathrm{H}_{2}$ generation and benzaldehyde (BAD) production from benzyl alcohol (BA) under visible-near-infrared irradiation. The molar ratio between $\mathrm{H}_{2}$ and $\mathrm{BAD}$ was $c a$. 1.0, indicting the stoichiometric dehydrogenation of $\mathrm{BA}$. The $\mathrm{H}_{2}$ production rates overAu@Pt@CdS and Au-Pt@CdS were about 13.4 and 21.2 times higher than that of blank CdS, respectively. The Au-Pt@CdS composite exhibited no obvious photoactivity decrease toward $\mathrm{H}_{2}$ and BAD production, indicating its excellent photostability. The underlying photocatalytic reaction mechanism was proposed. The electron-hole pairs were generated from $\mathrm{CdS}$ component under the irradiation of shortwavelength visible light $(420 \mathrm{~nm}<\lambda<520 \mathrm{~nm})$. The longer-wavelength light irradiation triggered the surface plasmon resonance (SPR) excitation of plasmonic Au-Pt bimetal, which offered extra electric field enhancement for enhancing the light absorption and facilitating the separation of electron-hole pairs in CdS. The electrons could efficiently transfer to the $\mathrm{Au}-\mathrm{Pt} \mathrm{NRs}$ and reacted with the $\mathrm{H}$ to form $\mathrm{H}_{2}$ gas. The retained holes oxidized the absorbed BA to produce BAD. Additionally, various dual-functional photocatalyst, such as $\mathrm{ZnS},{ }^{99} \mathrm{Zn}_{3} \mathrm{In}_{2} \mathrm{~S}_{6},{ }^{100} \mathrm{RuO}_{\mathrm{x}} / \mathrm{TiO}_{2},{ }^{101} \mathrm{Pt} / \mathrm{TiO}_{2},{ }^{102} \mathrm{Ni} / \mathrm{Zn}_{0.5} \mathrm{Cd}_{0.5} \mathrm{~S},{ }^{103} \mathrm{Au} / \mathrm{ZnIn}_{2} \mathrm{~S}_{4},{ }^{104} \mathrm{Co} / \mathrm{CdS},{ }^{105}$ $\mathrm{Ru} / \mathrm{SrTiO}_{3}: \mathrm{Rh},{ }^{106} \mathrm{NCN}^{\mathrm{CN}} \mathrm{X}-\mathrm{NiP},{ }^{107} \mathrm{Ni} / \mathrm{CdS},{ }^{96} \mathrm{Co}_{9} \mathrm{~S}_{8} / \mathrm{CdS}^{43}$ were fabricated for coupling $\mathrm{H}_{2}$ evolution with benzyl alcohol oxidation under light illumination. Recently, the merging of $\mathrm{H}_{2}$ production and furfural alcohol oxidation was also achieved over the $\mathrm{Ti}_{3} \mathrm{C}_{2} \mathrm{~T}_{\mathrm{x}} / \mathrm{CdS}$ composite under the irradiation of visible light $(\lambda>420 \mathrm{~nm}){ }^{108}$

Apart from aromatic alcohols, the selective conversion of different kinds of alkyl alcohols into corresponding aldehydes or ketones, accompanied with $\mathrm{H}_{2}$ evolution, has also been reported. ${ }^{109}$ Moreover, under the action of acidity or catalytic active sites, the as-formed aldehydes can undergo subsequent catalytic condensation reaction in dark to form long chain chemical products and added-value organics. This reaction is similar to the Suzuki-Miyaura reaction to produce long-chain compounds. ${ }^{44,110}$ For instance, Yanagida and co-workers demonstrated the conversion of organic substrates, such as methanol into ethylene glycol, tetrahydrofuran into 2,3-bis(diethylamino)butane, and triethylamine into 2,2'-bitetrahydrofuryl, with $\mathrm{H}_{2}$ evolution simultaneously, on colloidal $\mathrm{ZnS}$ photocatalyst under the illumination of UV light $(\lambda>$ $290 \mathrm{~nm}) .{ }^{111}$ Control experiments suggested that one-electron transfer from the photoexcited $\mathrm{ZnS}$ to the organic substrates could produce free carbon radicals through a proton loss. The condensation of these radicals with each other or with remaining carbonyl compounds formed new C-C bonds. This work effectively demonstrated the feasibility of carbon-carbon bond production via free radical intermediates. However, in-depth research into exact reaction mechanism was neglected.

Recently, $\mathrm{Lu}$ and co-workers found that, with traditional $\mathrm{TiO}_{2}$, 2,3-butanediol (2,3-BD) can be produced from ethanol via a C-C coupling reaction during $\mathrm{H}_{2}$ generation under the illumination of UV light $(\lambda=365 \mathrm{~nm}){ }^{22}$ For the untreated commercial $\mathrm{P} 25 \mathrm{TiO}_{2}$, the oxidized products, including acetaldehyde, acetic acid, and carbon dioxide, were detected rather than higher carbon products. After a pre-calcination the commercial P25 at different temperatures (marked as P25-X, where X represented the calcination temperature), the amounts of oxidation products significantly reduced in favor of 2,3-BD production. The best performance of $97 \%$ 2,3-BD selectivity and $1.85 \mathrm{mmol} \mathrm{g}^{-1} \mathrm{~h}^{-1} \mathrm{H}_{2}$ production were obtained for $1 \mathrm{wt} \%$ Pt decorated P25-900. After 60 hours reaction, the formation rates of $\mathrm{H}_{2}$ and 2,3-BD were $8.5 \mathrm{mmol} \mathrm{g}^{-1} \mathrm{~h}^{-1}$ and $4 \mathrm{mmol} \mathrm{g}^{-1} \mathrm{~h}^{-1}$, respectively. Moreover, the selectivity remained as high as $\sim 90 \%$, as shown in Figure 7B. During the reaction process, controlling the desorption of the initially produced $\alpha$-hydroxyethyl radicals 
to inhibit their continuous oxidation was of great importance. After calcination at $900{ }^{\circ} \mathrm{C}$, the crystal phase of P25 (anatase/rutile ratio is 80/20) transformed into pure rutile phase with a loss of the porous structure. This rutile phase $\mathrm{TiO}_{2}$ with less surface hydroxyl groups led to weak adsorption of $\alpha$-hydroxyethyl radicals, thus favoring the coupling reactions. Moreover, the porous structure of materials could trap the $\alpha$ hydroxyethyl radicals inside the pores that were easily further oxidized. A possible oxidation pathway for converting sacrificial ethanol into 2,3-BD during water splitting was proposed (Figure 7A). Under the illumination of UV light, semiconductor $\mathrm{TiO}_{2}$ can be excited to generate electron-hole pairs. The absorbed ethanol molecules were initially converted into $\alpha$-hydroxyethyl radicals attacked by one hole. The asformed $\alpha$-hydroxyethyl radicals further coupled to form 2,3-BD as a result of fast desorption over the treated samples, thus preventing the further oxidation. The photogenerated electrons transferred to the cocatalyst Pt to produce $\mathrm{H}_{2}$ gas. In another work, the effect $\cdot \mathrm{OH}$ amount on the 2,3-BD selectivity was systemically investigated by the same group. ${ }^{112}$ It was found that the higher the $\cdot \mathrm{OH}$ amount, the lower the 2,3-BD selectivity. Despite that a reasonable mechanism has been proposed, the detection of reaction intermediates is still unavailable.

Zhang et al. employed $\mathrm{CoP} / \mathrm{Zn}_{2} \mathrm{In}_{2} \mathrm{~S}_{5}$ photocatalyst to convert ethanol into 2,3-butanediol under the irradiation of visible light. ${ }^{29}$ Notably, when methanol was employed as the reactant, ethylene glycol (EG) was selectively formed and a proton-electron transfer mechanism was proposed (Figure 7C). The photogenerated holes from $\mathrm{Zn}_{2} \mathrm{In}_{2} \mathrm{~S}_{5}$ preferentially activated the $\mathrm{C}-\mathrm{H}$ bond instead of $\mathrm{O}-\mathrm{H}$ bond in methanol, producing a hydroxymethyl radical $\left(\cdot \mathrm{CH}_{2} \mathrm{OH}\right)$ with the release of one proton. Next, two $\cdot \mathrm{CH}_{2} \mathrm{OH}$ radicals combined via $\mathrm{C}-\mathrm{C}$ coupling to form one ethylene glycol (EG), while $\mathrm{H}_{2}$ was generated by the reduction of two protons by photogenerated electrons. Importantly, the formation of $\mathrm{CH}_{2} \mathrm{OH}$ intermediates has been detected via in situ electron spin resonance (ESR) spectroscopic study, which further validate the proposed reaction mechanism. As a result, the EG formation rate over $\mathrm{CoP} / \mathrm{Zn}_{2} \mathrm{In}_{2} \mathrm{~S}_{5}$ catalyst reached $5.5 \mathrm{mmol} \mathrm{g}_{\mathrm{cat}}{ }^{-1}$ $\mathrm{h}^{-1}$ under the illumination of visible light, as shown in Figure 7D. And the selectivity of EG was demonstrated to be $90 \%$. Moreover, there was no obvious deactivation within 6 recycling tests (Figure 7E), which indicated high stability of the $\mathrm{CoP} / \mathrm{Zn}_{2} \mathrm{In}_{2} \mathrm{~S}_{5}$ catalyst. The selective conversion of methanol to EG was more efficient over the $\mathrm{MoS}_{2}$ nanofoams decorated $\mathrm{CdS}$ nanorods $\left(\mathrm{MoS}_{2}\right.$ foam/CdS) photocatalyst. ${ }^{25}$ Upon the illumination of visible light $(420<\lambda<780 \mathrm{~nm})$, the $\mathrm{H}_{2}$ and EG production rates over the $\mathrm{MoS}_{2}$ foam/CdS composite were 12 and $11 \mathrm{mmol} \mathrm{g}_{\mathrm{cat}}{ }^{-1} \mathrm{~h}^{-1}$, respectively, and the selectivity of EG during the reaction process was as high as $90 \%$, which was attributed to the enrichment of $\mathrm{CH}_{2} \mathrm{OH}$ radicals intermediates inside the mesopores of $\mathrm{MoS}_{2}$ nanofoams. Recently, Zhou et al. employed the different noble metal single atom $(\mathrm{Ru}, \mathrm{Rh}, \mathrm{Pd}, \mathrm{Ag}$, Os, $\mathrm{Ir}, \mathrm{Pt}$, and $\mathrm{Au})$-loaded $\mathrm{TiO}_{2}\left(\mathrm{MSA}-\mathrm{TiO}_{2}\right)$ photocatalysts to active the $\mathrm{C}-\mathrm{H}$ bond in the stable acetone for producing 2,5-hexanedione (HDN) and $\mathrm{H}_{2}$ gas. ${ }^{113}$ The PtSA-TiO sample exhibited the best HDN-production rate $\left(3.87 \mathrm{mmol} \mathrm{g}^{-1} \mathrm{~h}^{-1}\right)$ from acetone with a selectivity of $93 \%$. During the reaction process, the attack of photogenerated holes from $\mathrm{TiO}_{2}$ dehydrogenated the acetone to form $\mathrm{CH}_{3} \mathrm{COCH}_{2}$ radicals, which were the critical intermediates to produce $\mathrm{HDN}$ via $\mathrm{C}-\mathrm{C}$ coupling. Then, the aggregated electrons in PtSA reduced the protons to generate $\mathrm{H}_{2}$ gas.

In addition to methanol and ethanol, Wang et al. showed that a series of aliphatic alcohols, including n-propanol, i-propanol, sec-butanol, and tert-butanol, can be coupled into corresponding dihydric alcohol, such as pinacol, 3,4-hexanediol, 3,4-dimethyl-3,4-hexanediol and 2,5-dimethyl-2,5-hexanediol, while simultaneously generating $\mathrm{H}_{2}$ over a $\mathrm{Pt} / \mathrm{TiO}_{2}$ nanotube photocatalyst. ${ }^{114}$ Similarly, the dual-functional photocatalytic system for conversing isopropanol into aliphatic pinacol accompanying with $\mathrm{H}_{2}$ production was also established. ${ }^{115,116}$ Moreover, a novel Pt-tipped CdSe@CdS rods photocatalysts were reported to produce hydrogen with 69\% photon-to-hydrogen conversion efficiency, along with simultaneous benzylamine $\left(\mathrm{BnNH}_{2}\right)$ oxidation to benzylidenebenzylamine and benzaldehyde under the illumination of visible light. ${ }^{117}$ The detailed mechanism study showed that the $\mathrm{BnNH}_{2}$ can firstly be converted into 
benzylidenebenzylamine, which could be further hydrolyzed to form benzaldehyde and $\mathrm{BnNH}_{2}$ with water. The newly formed $\mathrm{BnNH}_{2}$ was further oxidized under continuous light irradiation and shifted the latter reaction out of equilibrium toward the accumulation of benzaldehyde.

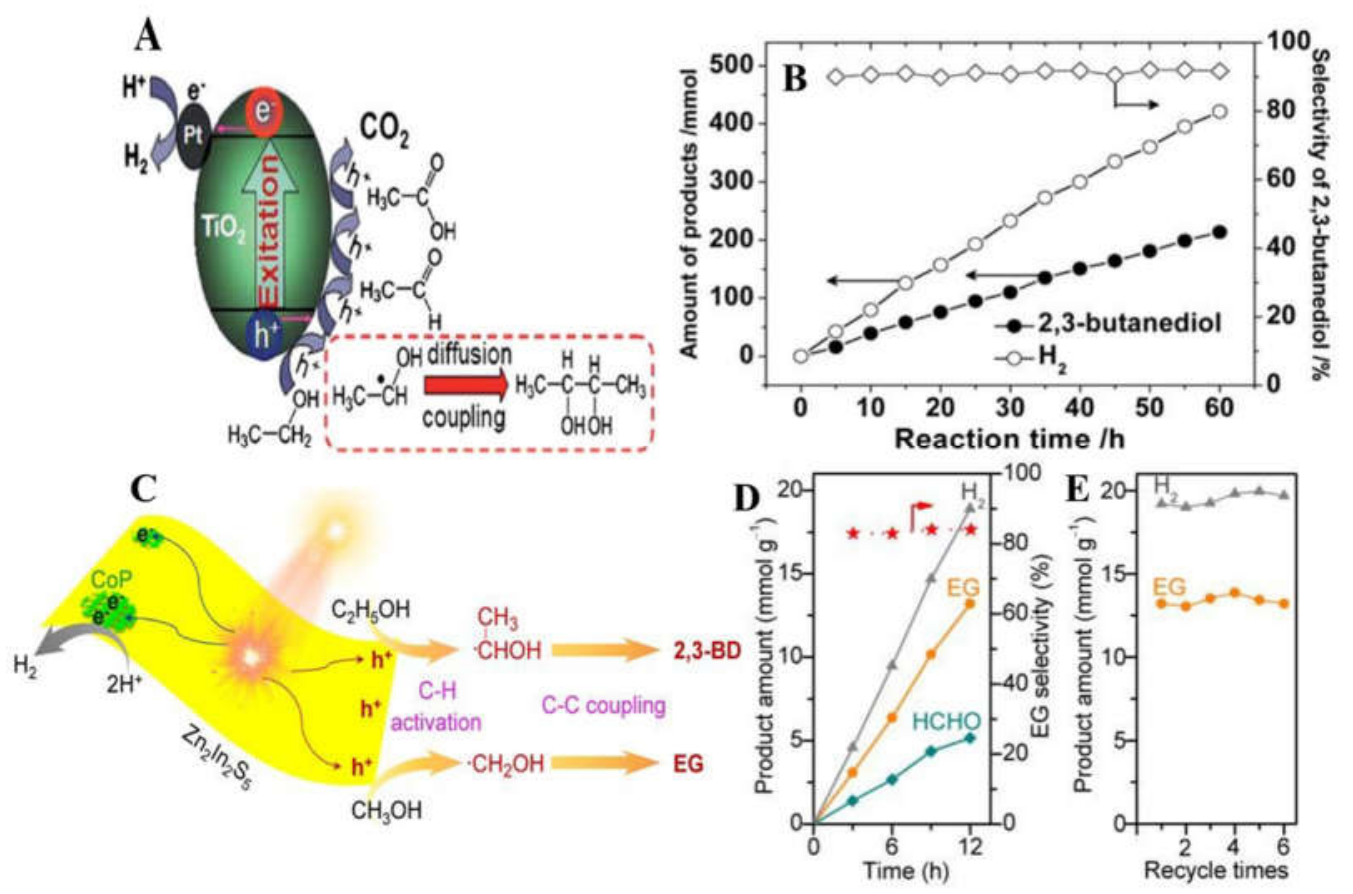

Figure 7 The possible oxidation pathways of ethanol during water splitting (A). Hydrogen evolution and 2,3-butanediol production over Pt-loaded $\mathrm{TiO}_{2}$ nanoparticles (B). Reproduced from $\mathrm{Ref}^{22}$. Copyright 2011 permission from the Royal Society of Chemistry. Photocatalytic conversions of methanol and ethanol to diols over $\mathrm{CoP} / \mathrm{Zn}_{2} \mathrm{In}_{2} \mathrm{~S}_{5}$ catalyst (C). Time course process of $\mathrm{Zn}_{2} \mathrm{In}_{2} \mathrm{~S}_{5}$ for MTEG within $12 \mathrm{~h}$ under visible light (D). Repeated use of $\mathrm{Zn}_{2} \mathrm{In}_{2} \mathrm{~S}_{5}$ under visible light (E). Reproduced from $\mathrm{Ref}^{29}$. Copyright 2020 permission from the Royal Society of Chemistry

Another alternative is to produce value-added acetals through the acid-catalyzed acetalation of aldehydes, formed via hole-induced dehydrogenation of alcohols, with unreacted alcohols, accompanying with $\mathrm{H}_{2}$ generation in neat alcohols. ${ }^{4}, 39,118-120$ Recently, Weng and co-workers combined $\mathrm{TiO}_{2}$ nanosheets (TNS) with Pd NPs and nanocubes (NCs) to TNS-Pd NPs composite (TPs) and TNS-Pd NCs composite (TCs- $\mathrm{x}$, where $\mathrm{x}$ represents Pd NCs size in $\mathrm{nm}$ ) for conversion of ethanol into 1,1-diethoxyethane (DEE) and $\mathrm{H}_{2}$ under the illumination of UV-Vis light $(300 \mathrm{~nm} \leq \lambda \leq 800 \mathrm{~nm}) .{ }^{39}$ Figure 8A and B revealed that the optimal material with $7 \mathrm{~nm}$ Pd NCs, TCs-7, exhibited the best activity for $\mathrm{H}_{2}$ generation $\left(51.5 \mathrm{mmol} \mathrm{g}^{-1} \mathrm{~h}^{-}\right.$ ${ }^{1}$ ) and DEE formation $\left(7.7 \mathrm{mmol} \mathrm{g}^{-1} \mathrm{~h}^{-1}\right)$. As described in Figure 8C and D, TCs-7 photocatalyst showed no obvious deactivation in seven consecutive cycles, indicating the excellent photostability of TCs-7 composite. The reaction mechanism for simultaneous $\mathrm{H}_{2}$ and DEE evolution was proposed. As shown in Figure 8E, upon UV light illumination, the photogenerated electrons and holes were generated in TNS. The electrons transferred to Pd NCs while the holes remained in TNS. The alkoxide anions were formed due to the deprotonation of adsorbed ethanol (process A). The interaction between alkoxide anions and holes produced corresponding carbon radicals and $\mathrm{H}^{+}$ions (process $\mathrm{B}$ ). Further oxidization of carbon radicals by holes led to the production of acetaldehydes (process $\mathrm{C}$ ). Notably, the acetaldehydes condensed with unreacted ethanol to form acetals (i.e., DEE) via the acid-catalytic acetalation reaction (process D). Simultaneously, the photoexcited electrons trapped by the Pd NCs reacted with the $\mathrm{H}^{+}$ions to form $\mathrm{H}_{2}$ fuel (process E).

The visible-light-driven dual-functional photocatalytic system for preparing value-added DEE and $\mathrm{H}_{2}$ 
by dehydrogenation and acetalization of ethanol was established by Chao and co-workers using nonprecious metal $\mathrm{CdS} / \mathrm{Ni}-\mathrm{MoS}_{2}$ catalyst. ${ }^{118}$ Analogously, the methanol was photocatalytic dehydrogenated and then converted to the corresponding 1,1-dimethoxymethane and $\mathrm{H}_{2}$ in the neat methanol solution through the tandem dehydrogenation-acetalization process under the irradiation of visible light $(\lambda>420$ $\mathrm{nm}) .{ }^{119}$ Systemically, Zhang et al. demonstrated the photocatalytic conversion of different kinds of alcohol into corresponding acetals and $\mathrm{H}_{2}$ by various noble metals ( $\mathrm{Pt}, \mathrm{Pd}, \mathrm{Au}$ and $\mathrm{Ru}$ ) modified $\mathrm{TiO}_{2}$ under the illumination of UV light. ${ }^{5}$
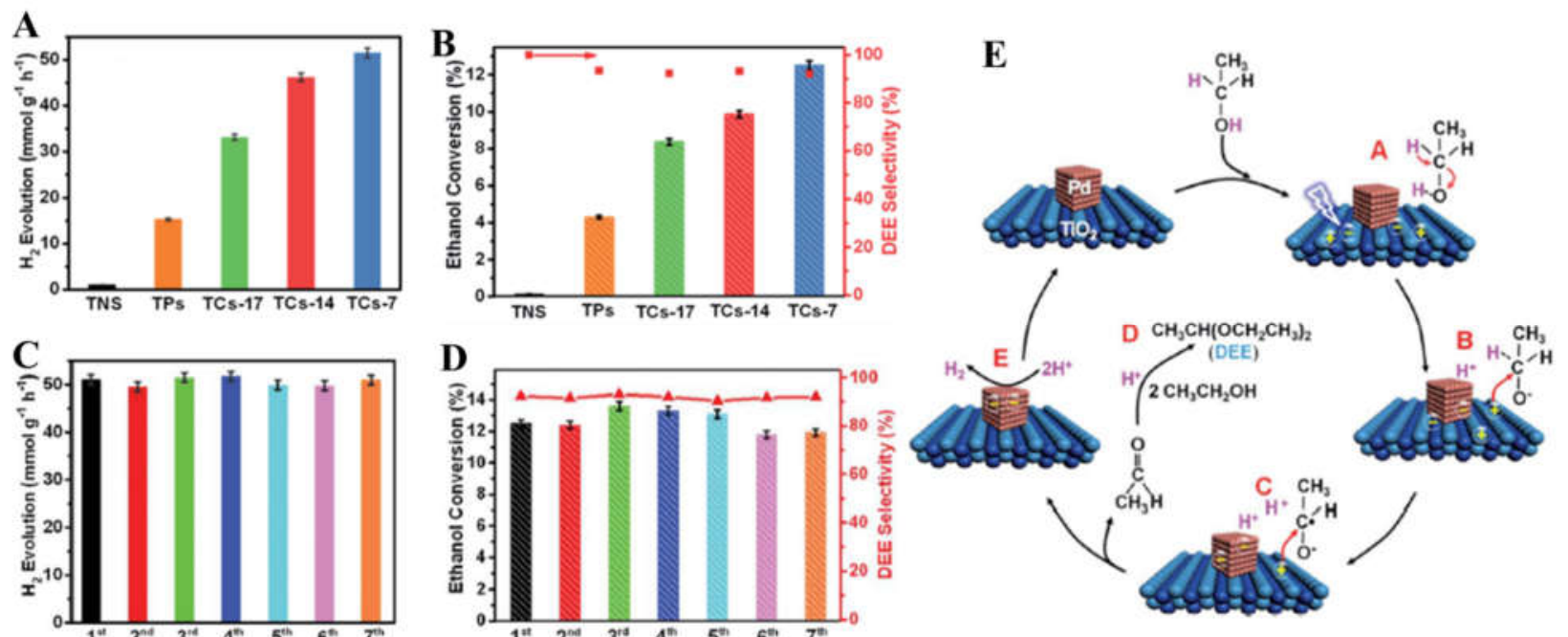

Figure 8 Photocatalytic $\mathrm{H}_{2}$ evolution over different samples (A); Photocatalytic ethanol conversion and DEE selectivity over different samples (B); Recycling photocatalytic $\mathrm{H}_{2}$ evolution over TCs-7 sample (C); Ethanol conversion and DEE selectivity (D); Reaction mechanism of simultaneous formation for $\mathrm{H}_{2}$ and DEE (E). Reproduced from Ref ${ }^{39}$. Copyright 2016 permission from the Royal Society of Chemistry.

For the photocatalytic oxidation of various alcohols coupled with $\mathrm{H}_{2}$ evolution system, most of the reported photocatalysts are consistent with various precious metals (e.g., $\mathrm{Pt}, \mathrm{Pd}, \mathrm{Au}$ and $\mathrm{Ru}$ ), which would potentially restrict their large-scale and practical applications due to their high cost and low crustal reserve. Therefore, the development of non-noble metal alternatives materials for coupling $\mathrm{H}_{2}$ evolution with oxidation of various alcohols is crucial and necessary. In addition, the research attention has been paid on the modification of cocatalysts for $\mathrm{H}_{2}$ production, while the explorement of suitable cocatalysts toward alcohols oxidation is still limited. Considering that the transport of photo-induced holes is problematic and generally slow as compoared with that of electrons, the reaction kinetics of alcohols oxidation would be limited. Thus, it is highly desired to fabricate and design effcient oxdiation cocatalysts to extract the holes from semiconductor, and then enhance the kinetics of hole transfer. Furthermore, the development of dual cocatalysts systems containing both reduction and oxidation cocatalysts is excepted to efficiently captrue the photogenerated electron and holes, respectively, thus promoting the photocatalytic performace of dualfunctional reactions. However, the reports on the fabrication of such dual cocatalysts systems toward oxidation of various alcohols coupled with $\mathrm{H}_{2}$ evolution are rare.

\subsection{Photocatalytic generation of value-added oxidized organics coupled with hydrogen evolution}

Apart from different alcohols, various other organic compounds have been employed as reactants to yield value-added chemical products in combination with $\mathrm{H}_{2}$ evolution. For instance, Cao et al. decorated cobalt phosphide $\left(\mathrm{Co}_{2} \mathrm{P}\right) \mathrm{NPs}$ onto $\mathrm{CdS}$ NRs for photocatalytic $\mathrm{H}_{2}$ generation, and simultaneously, DL- 
mandelic acid to benzoylformic acid conversion. ${ }^{121}$ Under white LED light irradiation $(\lambda \geq 420 \mathrm{~nm})$ for 10 $\mathrm{h}$, the optimal system, containing $2.3 \times 10^{-4} \mathrm{M} \mathrm{CdS}$ NRs and $1.0 \times 10^{-4} \mathrm{M} \mathrm{Co}_{2} \mathrm{P} \mathrm{NPs}$, exhibited the highest $\mathrm{H}_{2}$ production rate of $19.4 \mu \mathrm{mol} \mathrm{h}^{-1} \mathrm{~g}^{-1}$. The benzoylformic acid was the only product as confirmed by ESIMS analysis. However, the formation rate of benzoylformic acid was not studied in this work. Moreover, the photocatalytic reaction mechanism was unclear. The first work regarding the imidazole synthesis via visible-light-driven cyclization of amines over Mo doped $\mathrm{InZn}_{2} \mathrm{~S}_{4}\left(\mathrm{Mo}-\mathrm{ZnIn}_{2} \mathrm{~S}_{4}\right)$ photocatalyst was reported by Wang and co-workers. ${ }^{38}$ The Mo-ZnIn ${ }_{2} \mathrm{~S}_{4}$ photocatalyst converted $99 \%$ benzylamine into corresponding tri- and tetra-substituted imidazoles (96\% total yields) by C-C/C-N coupling after 10 hours reaction. Nevertheless, the exact production amount of $\mathrm{H}_{2}$ gas during the photocyclization of amine process was not detected. A tentative reaction mechanism was proposed. Upon the illumination of visible light, the Mo$\mathrm{ZnIn}_{2} \mathrm{~S}_{4}$ catalyst generated electrons and holes. The amines and imines were oxidized to generate nitrogencentered radical cations by a single-electron-transfer process. Subsequently, in a proton transfer process, the benzyl C-H bond and carbon-centered radicals were activated by the nitrogen-centered radical cations, and the electrons reduced two protons into one $\mathrm{H}_{2}$ molecule. Meanwhile, the coupling and dehydrogenation of the benzylamine radicals with imine radicals generated tri-substituted imidazoles. Further, the coupling of imines and dibenzylamine radicals eventually yielded tetra-substituted imidazoles.

Recently, furfuryl alcohol and its oxidative derivatives could also be produced via a dual-functional photocatalytic reaction system. ${ }^{37}$ For instance, Han et al. investigated the conversion of furfuryl alcohol and 5-hydroxymethylfurfural (HMF) into value-added furfural and 2,5-diformylfuran (DFF), respectively, in combination with $\mathrm{H}_{2}$ generation, using ultrathin $\mathrm{CdS}$ nanosheets decorated with nickel composite $(\mathrm{Ni} / \mathrm{CdS})$ as photocatalysts under the illumination of visible light $(\lambda=450 \mathrm{~nm}) .{ }^{122}$ Nearly $100 \%$ furfural alcohol was converted to furfural after $22 \mathrm{~h}$ photocatalytic reaction, while only $20 \%$ conversion of HMF into DFF was achieved under the same conditions. This was ascribed to the slightly stronger binding affinity of the aldehyde group between HMF and Ni/CdS, thus affecting the oxidation of HMF. Notably, the conversion of furfural alcohol and HMF was significantly improved under strongly alkaline conditions $(10 \mathrm{M} \mathrm{NaOH})$. Therefore, photocatalytic complete conversion of furfural alcohol and HMF was realized with the concomitant production of $\mathrm{H}_{2}$ under the illumination of visible light. However, the underlying reaction mechanisms for the conversion of furfuryl alcohol and HMF were not elucidated yet. Notably, this reaction mechanism was further investigated by Luo and co-workers using Ru doped $\mathrm{ZnIn}_{2} \mathrm{~S}_{4}$ nanoflowers composite $\left(\mathrm{Ru}-\mathrm{ZnIn}_{2} \mathrm{~S}_{4}\right){ }^{123}$ among which the $\mathrm{Ru}$ atoms were believed to replace the indium ions in the semiconductor $\mathrm{ZnIn}_{2} \mathrm{~S}_{4}$ (Figure 9A). The $\mathrm{Ru}-\mathrm{ZnIn}_{2} \mathrm{~S}_{4}$ sample catalyzed the dehydrocoupling of 2,5-

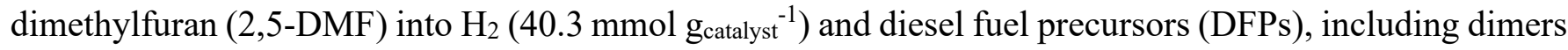
$\left(\mathrm{C}_{12}, 4.69 \mathrm{~g} \mathrm{~g}_{\text {catalyst }}{ }^{-1}\right)$, trimers $\left(\mathrm{C}_{18}, 1.84 \mathrm{~g} \mathrm{~g}_{\text {catalyst }}{ }^{-1}\right)$ and a small amount of tetramers $\left(\mathrm{C}_{24}, 0.24 \mathrm{~g} \mathrm{~g}_{\text {catalyst }}{ }^{-1}\right)$ under the irradiation of visible light $(\lambda=455 \mathrm{~nm})$, as illustrated in Figure 9B. The production rate of $\mathrm{H}_{2}$ and total liquid products were matched, indicating that electrons and holes were consumed simultaneously. After 100 hours, no significant structure change was observed in the selectivity of DFPs (97\%) and branched-chain DFPs (43\%), suggesting the photostability of the Ru-ZnIn $\mathrm{S}_{4}$ composite. The mechanism of 2,5-DMF dehydrocoupling over $\mathrm{ZnIn}_{2} \mathrm{~S}_{4}$ sample was proposed in Figure 9C. Upon visible light irradiation, the photoexcited holes in the VB of Ru- $\mathrm{ZnIn}_{2} \mathrm{~S}_{4}$ oxidized the furfuryl C-H bond of 2,5-DMF, producing protons and furfuryl radicals. The as-formed furfuryl radicals underwent resonance to produce dimeric isomers via $\mathrm{C}-\mathrm{C}$ coupling reactions. The trimers and tetramers were formed due to the reaction between dimers and 2,5-DMF (or themselves). Simultaneously, the protons were reduced by the electrons from $\mathrm{Ru}-\mathrm{ZnIn}_{2} \mathrm{~S}_{4}$ to yield $\mathrm{H}_{2}$ fuel. 

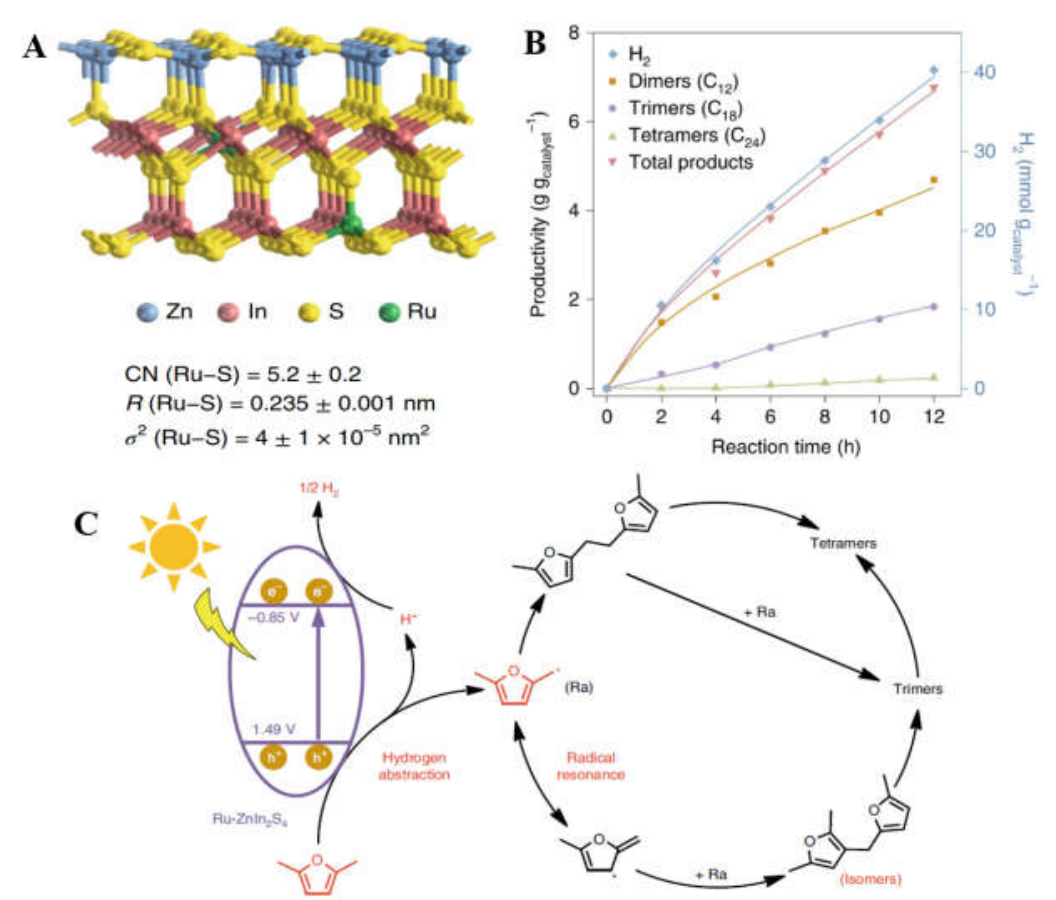

Figure 9 The $\mathrm{Ru}-\mathrm{ZnIn}_{2} \mathrm{~S}_{4}$ structure and the fitting results of Ru-S coordination (A); Photocatalytic conversion of 2,5-DMF into diesel fuel (B); Suggested mechanism for photocatalytic dehydrocoupling of 2,5-DMF (C). Reproduced from Ref $^{123}$. Copyright 2019 permission from Springer Nature.

Another interesting work is the photo-transformation of food waste into $\mathrm{H}_{2}$ and formate over both the $\mathrm{CdS} / \mathrm{CdO}_{\mathrm{x}}$ and ${ }^{\mathrm{H} 2 \mathrm{~N}} \mathrm{CN}_{\mathrm{x}} \mid \mathrm{Ni}_{2} \mathrm{P}$ photocatalyst, as reported by Erwin and co-workers. ${ }^{124}$ The results showed that a variety of fats, such as amino acid, glutamic acid, proteins can be photo-reformed over $\mathrm{CdS} / \mathrm{CdO}$ and ${ }^{\mathrm{H} 2 \mathrm{~N}} \mathrm{CN}_{x} \mid \mathrm{Ni}_{2} \mathrm{P}$ to produce $\mathrm{H}_{2}$ gas and formate. The ${ }^{\mathrm{H} 2 \mathrm{~N}} \mathrm{CN}_{x} \mid \mathrm{Ni}_{2} \mathrm{P}$ catalyst exhibited high versatility over a wide $\mathrm{pH}$ range and was non-toxicity with a small carbon footprint, while the $\mathrm{CdS} / \mathrm{CdO}_{x}$ composite produced more $\mathrm{H}_{2}$ and formate in alkaline conditions. Moreover, both the $\mathrm{CdS} / \mathrm{CdO}_{x}$ and ${ }^{\mathrm{H} 2 \mathrm{~N}} \mathrm{CN}_{x} \mid \mathrm{Ni}_{2} \mathrm{P}$ composites converted real-world municipal waste into $\mathrm{H}_{2}$ under all conditions despite the efficiency was low. These results demonstrated the unique applicability to photo-reform the non-recyclable mixed waste. However, the oxidation products in this reaction system were complex and some unidentified oxidation products were detected. Moreover, the detailed photocatalytic reaction mechanisms for the conversion of organic substrate were still unclear and more research attention should be paid in this regard. Furthermore, a comparative summary of photocatalytic oxidation of various alcohols coupled with $\mathrm{H}_{2}$ evolution is listed in Table $\mathbf{S 4}$.

\subsection{Selective photocatalytic alcohol oxidation coupled with $\mathrm{CO}_{2}$ reduction}

$\mathrm{CO}_{2}$ is a potential carbon resource with abundant reserves and stable performance. In the context of the energy crisis and environmental pollution where fossil energy consumption is soaring and $\mathrm{CO}_{2}$ emissions are increasing, the implementation of $\mathrm{CO}_{2}$ conversion technology is of enormous importance. Photocatalytic $\mathrm{CO}_{2}$ reduction is one promising approach to release the crisis of energy and reduce the atmospheric $\mathrm{CO}_{2}$ accumulation. Recently, coupling $\mathrm{CO}_{2}$ photoreduction with selective organic oxidation to simultaneously generate fuels and various organic products has received considerable attention, which plays a pivotal role to the realization of a carbon neutral and sustainable development. ${ }^{42,123,125-127}$ For example, Yang and co-workers employed the $\mathrm{Cu} / \mathrm{TiO}_{2}$ photocatalysts to reduce $\mathrm{CO}_{2}$ into $\mathrm{CH}_{3} \mathrm{OH}$ and simultaneously oxidize amine to imine under the illumination of UV light $(\lambda=365 \mathrm{~nm}) .{ }^{126}$ After $15 \mathrm{~h}$ of reaction, the optimal photocatalyst of $0.5 \mathrm{wt} \% \mathrm{Cu} / \mathrm{TiO}_{2}$ exhibited the maximum conversion of benzylamine to N-benzylidenebenzylamine (89\%) with a high selectivity of $98 \%$, and the $\mathrm{CH}_{3} \mathrm{OH}$ yield was $961.4 \mu \mathrm{mol}$ 
$\mathrm{g}^{-1}$. The yield of $\mathrm{CH}_{3} \mathrm{OH}$ and the conversion of amines were affected by different kinds of methylsubstituted benzylamine (at ortho-, meta-, para-positions of the benzene ring). The photoactivity order was ortho- $>$ meta- $>$ para-, indicating the large effect of steric hindrance on the catalytic activity. Moreover, the electron-donating groups $\left(\mathrm{CH}_{3} \mathrm{O}-\right.$ and $\left.\mathrm{CH}_{3}-\right)$ in the aromatic rings were beneficial toward benzylamine oxidation and $\mathrm{CH}_{3} \mathrm{OH}$ production as compared to the electron-withdrawing groups (F- and $\mathrm{Cl}-$ ). Additionally, the same group showed the feasibility of merging $\mathrm{CO}_{2}$ reduction to $\mathrm{CH}_{3} \mathrm{OH}$ with the selective aromatic alcohols oxidation using a $\mathrm{Ag} / \mathrm{TiO}_{2}$ composite under the illumination of UV light $(\lambda=365 \mathrm{~nm}) .{ }^{127}$ Recently, Huang et al. also investigated the coupling of $\mathrm{CO}_{2}$-to-CO photoreduction and benzyl alcohol oxidation to benzaldehyde over $\mathrm{FAPbBr} 3 / \mathrm{Bi}_{2} \mathrm{WO}_{6}$ composites under simulated solar illumination (AM1.5G filter). ${ }^{42}$

Guo et al. reported the simultaneously oxidizing 1-phenylethanol into pinacols and reducing $\mathrm{CO}_{2}$ to $\mathrm{CO}$ using colloidal $\mathrm{CdSe} / \mathrm{CdS}$ quantum dots (QDs) as catalysts under the illumination of visible light. ${ }^{125}$ The results showed that the yield of pinacols was $74 \%$ with the formation rate of $26.5 \mathrm{mmol} \mathrm{g}^{-1} \mathrm{~h}^{-1}$ and the selectivity of CO was $94 \%$ with the evolution rate of $27.6 \mathrm{mmol} \mathrm{g}^{-1} \mathrm{~h}^{-1}$ over the CdSe/CdS QDs photocatalyst. Notably, the presence of electron-donating groups in aryl ring (such as $-\mathrm{OCH}_{3}$ ) was beneficial for promoting the pinacols production, while electron-withdrawing groups in aryl ring (e.g., - $\mathrm{NO}_{2}$ ) obviously declined the yield of pinacols. A tentative reaction mechanism toward simultaneously $\mathrm{CO}_{2}$ reduction and 1-phenylethanol oxidation was proposed (Figure 10A). Upon light illumination, the photogenerated holes from QDs oxidized the 1-phenylethanols to yield $\mathrm{H}^{+}$and carbon-centered radicals. The pinacols were formed via $\mathrm{C}-\mathrm{C}$ coupling of these carbon-centered radicals. Moreover, the mechanism of $\mathrm{CO}_{2}$-to-CO conversion was also investigated detailly (Figure 10B). The Se-vacancy on the surface of $\mathrm{CdSe}$ was favorable for adsorbing $\mathrm{CO}_{2}$ molecules and activated the adsorbed $\mathrm{CO}_{2}$ by distorting the linear structure to bend configuration. The interaction between activated $\mathrm{CO}_{2}$ molecules and protons in the presence of electrons generated the $\mathrm{COOH}^{*}$ intermediates. The further reduction of these intermediates led to the formation of $\mathrm{CO}^{*}$ and $\mathrm{OH}^{*}$ intermediates. The detach of $\mathrm{CO}^{*}$ from the catalyst surface formed $\mathrm{CO}$ gas. The strong adsorption of $\mathrm{COOH}^{*}$ and desorption of $\mathrm{CO}^{*}$ intermediates made $\mathrm{CO}$ as a sole carbonbased product, i.e., high selectivity. The coupling of photocatalytic selective organic transformation with $\mathrm{CO}_{2}$ reduction made full use of photogenerated charge carriers to simultaneously create value-added chemicals and solar fuel (CO). Furthermore, the oxidation and reduction products were separated in the solution and gaseous phase spontaneously.

Similar work was also reported by Yuan et al. using surfactant functionalized $\mathrm{ZnIn}_{2} \mathrm{~S}_{4}$ (CTAB-ZIS) with structural defects for coupling $\mathrm{CO}_{2}$ reduction with the benzyl alcohol oxidation. ${ }^{128}$ Under the illumination of visible light $(\lambda>420 \mathrm{~nm})$ for $7 \mathrm{~h}$, both $\mathrm{CO}(2.65 \mu \mathrm{mol})$ and $\mathrm{H}_{2}(45.07 \mu \mathrm{mol})$ were detected in the gas phase products, meanwhile, the conversion of BA was demonstrated to be $99 \%$, and the selectivity of BAD and C-C coupling products (e.g., hydrobenzoin and benzoin) were $31 \%$ and 69\%, respectively. Mechanism study showed that the BA was oxidized by the holes from CTAB-ZIS to form $\alpha$-hydroxybenzyl radicals ( $\mathrm{C} \alpha$ radicals) and then $\mathrm{BAD}$. Moreover, the as-formed $\mathrm{C} \alpha$ radicals also combined to form hydrobenzoin via $\mathrm{C}-\mathrm{C}$ coupling reaction, which could further be oxidized to produce benzoin. At the same time, the photogenerated electrons reduced the $\mathrm{CO}_{2}$ reactants to $\mathrm{CO}$ molecules, and the hydrogen ions denoted by BA were favorable for the production of hydrogen gas. A comparative summary of photocatalytic alcohol oxidation coupled with $\mathrm{CO}_{2}$ reduction is listed in Table $\mathbf{S 5}$. 

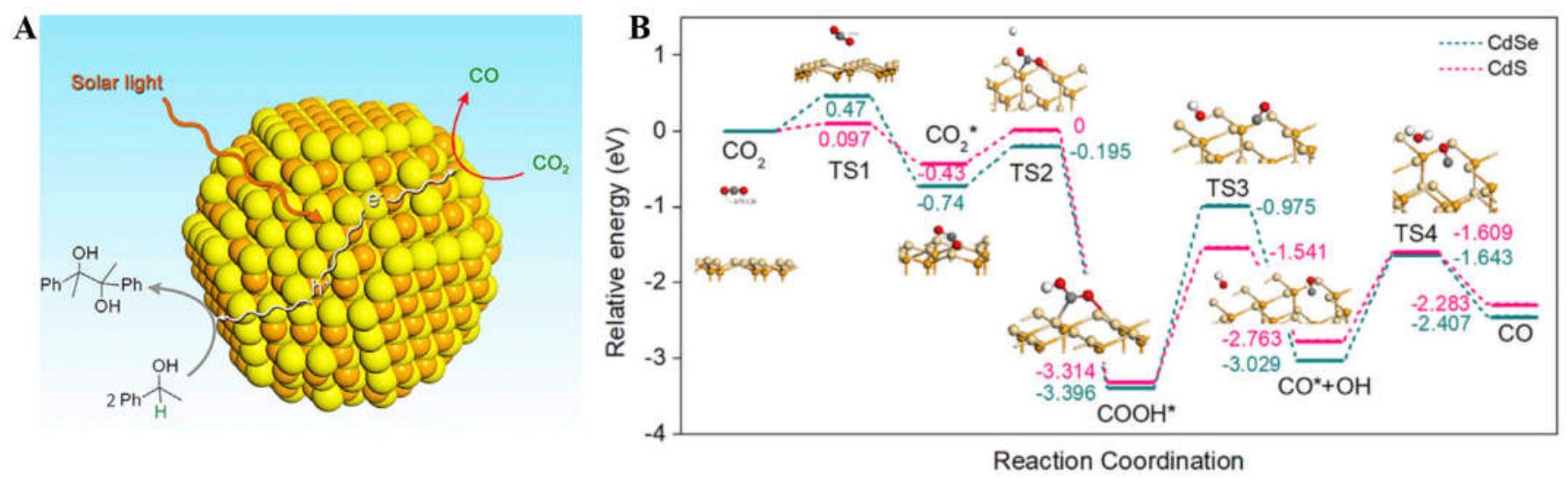

Figure 10 Photocatalytic $\mathrm{CO}_{2}$ reduction coupled with oxidative organic synthesis by CdSe/CdS QDs (A); Full potential energy for the adsorption and dissociation of $\mathrm{CO}_{2}$ via proton-coupled electron transfer to generate $\mathrm{CO}$ on cubic CdSe or CdS (111) facet (gray, red, white, buff, and yellow atoms represent C, O, H, $\mathrm{Cd}$ and Se (S) atoms, respectively) (B). Reproduced from Ref ${ }^{125}$. Copyright 2019 permission from Elsevier.

Up to now, only limited works for merging photocatalytic $\mathrm{CO}_{2}$ reduction with selective alcohol oxidation have been reported and the research is still at an early stage. There are still some critical issues needed to be solved. For instance, in the reaction system, three phases, including photocatalyst (solid), $\mathrm{CO}_{2}$ (gas) and reaction solution (liquid), are exist simultaneously and the contact among them may be insufficient, which could lead to mass-transfer and proton contact limitations, thus constituting a significant hurdle for highly efficient $\mathrm{CO}_{2}$ reduction and alcohol oxidation. Therefore, it is urgent to enhance the concentration of $\mathrm{CO}_{2}$ and improve its diffusivity in solution to tackle the transfer limitations for promoting the overall photocatalytic efficiency. Moreover, to trigger the $\mathrm{CO}_{2}$ reduction with selective alcohol oxidation in one reaction system, the as-designed photocatalyst is suggested to offer a large driving force to provide sufficient reduction and oxidation potentials. Notably, the redox ability of composite photocatalyst with traditional type-II heterostructure is compromised, leading to the lower redox potential of photoexcited electrons/holes. Thus, the construction of Z-scheme heterojunction composites, which could preserve the strong redox ability of charge carriers whilst efficiently separating the electrons and holes pairs, is highly recommended to achieve large driving force toward photocatalytic $\mathrm{CO}_{2}$ reduction coupled with selective alcohol oxidation. Furthermore, in most cases, the photocatalytic $\mathrm{CO}_{2}$ reduction and alcohol oxidation generate more than two different redox products and the redox reactions are occurred independently. If we can realize the photocatalytic carboxylation of $\mathrm{C}-\mathrm{H}$ bond from the alcohol with $\mathrm{CO}_{2}$ as the $\mathrm{C} 1$ synthon to achieve the $\mathrm{C}-\mathrm{C}$ chain growth, the research would be more interesting and meaningful.

\section{Summary and outlook}

Dual-functional photocatalytic reaction systems combining selective organic transformation have recently received considerable attention because of the perspective of economic and social sustainability. In this review, the development of dual-functional photocatalysis for selective organic conversion to produce value-added chemical products is systemically summarized. This review is compartmentalized into two classes based on the targeted redox reactions, i.e., merging the selective oxidation of organic compounds with selective reductions for chemicals production or fuel generation (e.g., $\mathrm{H}_{2}, \mathrm{CO}$ ). For the different processes reported in literatures, feasible reaction mechanisms are discussed and some personal perspectives in this scientific area have been proposed.

Firstly, to bring these experimental results to practical applications, the research attention should be paid to design efficient, chemically stable, and visible light-responsive semiconductor materials to maximize their photocatalytic activity. Specifically, the structural and/or electronic properties of 
semiconductors are significantly affected by their crystal structure, size, and morphology, which represents a feasible strategy to fabricate semiconductor-based composite with high performance. Moreover, doping, metal loading, and/or heterojunctions construction with semiconductors are demonstrated to obviously enhance the spatial separation of photoexcited electron-hole pairs, thus promoting the photocatalytic efficiency of dual-functional reaction systems. Additionally, the interface structures in the heterojunctions are also of significant importance to tuning the charge kinetics, which could bound up with the capability to enhance the photoactivity. Thus, to develop next-generation of dual-functional photocatalysts for selective organic transformations, the researcher should take these parameters into consideration and design the composites materials at the system level which not only accentuates the modification of the individual components but also emphasizes the optimization of interfacial contact.

Secondly, the reaction mechanisms for the production of various valuable chemical products using photogenerated electrons and holes concurrently are controversial. For instance, as for the dual-functional photocatalytic C-C cross-coupling reactions, such as Suzuki, Sonogashira, the metal Pd NPs are generally involved in the composite photocatalysts, which can not only act as electron sinks to accept photogenerated electrons but also serve as thermal reaction centers to activate the reactants and trigger the cross-coupling reaction. However, researches for determining thermo- and photocatalytic activity over the Pd-based catalysts are still neglected. Moreover, the presence of different alcohols as solvent could consume photogenerated holes in the reaction system, whereas its effect on the photocatalytic performance and underlying mechanism is still unknown. Therefore, the investigation of reaction mechanisms for the dualfunctional reaction systems to disclose the detailed reaction routes is of great importance. In this regard, the employment of some advanced technologies such as gas chromatography-mass spectrometry (GC-MS), nuclear magnetic resonance (NMR), isotope labeling, in situ electron paramagnetic resonance (in situ EPR), in situ X-ray absorption spectroscopy (in situ XAS) and in situ Fourier-transform infrared spectroscopy (in situ FTIR) are critical to detect and capture the reaction intermediates, thus providing validated experiment data to support the proposed mechanisms for dual-functional organic transformation.

Thirdly, the selectivity of the desired products should be further improved to reduce the amounts of byproducts. To achieve this goal, the delicate design of suitable photocatalysts to equilibrate the absorbance of reactants and desorption of intermediates or products is one viable approach. Also, the new reactor design to separate the preferable products from the reaction system could be another feasible strategy for high selectivity. For instance, a process-intensified reactor has been invented to perform simultaneous ethylene glycol separation from methanol solvent during the reaction, which thus provides a high ethylene glycol selectivity (90\%) during the longtime reaction as compared with the conventional reactor. ${ }^{25}$

Last but not least, despite exciting advances in this emerging field, most experiments are still carried out on a small laboratory scale. The tentative move from the laboratory to a large-scale reaction for the above-mentioned valuable chemicals is still unavailable. Moreover, the traditional batch reactors generally suffer from low conversion and over-oxidation of target products. Therefore, carrying out the dualfunctional photocatalytic selective organic transformation using a continuous-flow reactor to minimize potential byproduct formation, uniformly illuminate the whole reaction solution, and reduce the inner filter effect of the concentrated photocatalyst and/or product is a more practical way to harvest and convey photons to the reaction media. Several segmented tubular units could link with each other to constitute the continuous-flow reactor, among which a light source with photocatalyst coated casings is located in the center of each tubular unit. The continuous feeding of the reactants could be achieved by a circulation pump. Such configuration ensures the uniform light distribution and the sufficient contact between the photocatalysts and reactants, which is beneficial for enhancing the efficiency of the whole system.

\section{Acknowledgements}


This work was financially supported by the National Natural Science Foundation of China (21902132, 22072113); and the CAS Key Lab of Colloids, Interfaces, and Thermal Dynamics; the European Union's Horizon 2020 research and innovation programme under the Marie Skłodowska-Curie grant agreement No. 891276; Research Foundation-Flanders (FWO, grant No. 1280021N); the KU Leuven Research Fund (C14/15/053 and C14/19/079), and the European Union (Horizon 2020) Marie Sklodowska-Curie innovation program (Grant 722591) for a Ph.D. scholarship.

\section{Abbreviations}

AL Aniline

BA Benzyl alcohol

BAD Benzaldehyde

$\mathrm{B}-\mathrm{BO}_{3} \quad$ Poly(benzoxadiazole) network

$\mathrm{BnNH}_{2} \quad$ Benzylamine

CB Conduction band

CTAB Cetyltrimethylammonium bromide

DEE 1,1-diethoxyethane

DFF 2,5-diformylfuran

DFT Density functional theory

DMPO 5,5-dimethyl-1-pyrroline-N-oxide

DFPs Diesel fuel precursors

EG Ethylene glycol

$\mathrm{E}_{\mathrm{vb}} \quad$ Valence band top potential

HDN 2,5-hexanedione

HMF 5-hydroxymethylfurfural

MPA 3-mercaptopropionic acid

mpg- $\mathrm{C}_{3} \mathrm{~N}_{4} \quad$ Mesoporous graphitic carbon nitride

NB Nitrobenzene

NC Nanocube

NP Nanoparticle

NR Nanorod

NSB Nitrosobenzene

PDA Polydopamine

p-MBA p-methoxybenzyl alcohol

p-MBAD p-methoxybenzaldehyde

PP-ol 2-phenoxy-1-phenylethanol

QDs Quantum dots

SHE Standard hydrogen electrode

SO Selective oxidation

SPR Surface plasmon resonance

SR Selective reduction

TEOA Triethanolamine

TN $\quad \mathrm{TiO}_{2}$ nanosheet

TP $\quad \mathrm{TiO}_{2}$ nanosheet-Pd nanoparticle

UV Ultraviolet

VB Valence band

Vis-NIR Visible-near-infrared 


$\begin{array}{ll}\text { ZIS } & \mathrm{ZnIn}_{2} \mathrm{~S}_{4} \\ \text { 2,3-BD } & \text { 2,3-butanediol } \\ \text { 2,5-DMF } & \text { 2,5-dimethylfuran } \\ \mathrm{h} & \text { Planck's constant } \\ v & \text { Incident light frequency } \\ \mathrm{h}^{+} & \text {Photogenerated hole } \\ \mathrm{e}^{-} & \text {Photogenerated electron } \\ \lambda & \text { Incident light wavelength }\end{array}$

\section{Conflicts of interest}

The authors declare no conflict of interest.

\section{References}

1. Augugliaro, V.; Bellardita, M.; Loddo, V.; Palmisano, G.; Palmisano, L.; Yurdakal, S., Overview on Oxidation Mechanisms of Organic Compounds by $\mathrm{TiO}_{2}$ in Heterogeneous Photocatalysis. $J$. Photochem. Photobiol. C 2012, 13, 224-245.

2. Chen, J.; Cen, J.; Xu, X.; Li, X., The Application of Heterogeneous Visible Light Photocatalysts in Organic Synthesis. Catal. Sci. Technol. 2016, 6, 349-362.

3. Palmisano, G.; García-López, E.; Marcì, G.; Loddo, V.; Yurdakal, S.; Augugliaro, V.; Palmisano, L., Advances in Selective Conversions by Heterogeneous Photocatalysis. Chem. Commun. 2010, 46, 7074-7089.

4. Zhang, H.; Zhu, Z.; Wu, Y.; Zhao, T.; Li, L., TiO 2 -Photocatalytic Acceptorless Dehydrogenation Coupling of Primary Alkyl Alcohols into Acetals. Green Chem. 2014, 16, 4076-4080.

5. Friedmann, D.; Hakki, A.; Kim, H.; Choi, W.; Bahnemann, D., Heterogeneous Photocatalytic Organic Synthesis: State-of-the-Art and Future Perspectives. Green Chem. 2016, 18, 5391-5411.

6. Climent, M. J.; Corma, A.; Iborra, S., Heterogeneous Catalysts for the One-Pot Synthesis of Chemicals and Fine Chemicals. Chem. Rev. 2011, 111, 1072-1133.

7. Weng, B.; Qi, M.-Y.; Han, C.; Tang, Z.-R.; Xu, Y.-J., Photocorrosion Inhibition of SemiconductorBased Photocatalysts: Basic Principle, Current Development, and Future Perspective. ACS Catal. 2019, 9, 4642-4687.

8. Palmisano, G.; Augugliaro, V.; Pagliaro, M.; Palmisano, L., Photocatalysis: A Promising Route for 21st Century Organic Chemistry. Chem. Commun. 2007, 33, 3425-3437.

9. Zhang, N.; Yang, M.-Q.; Liu, S.; Sun, Y.; Xu, Y.-J., Waltzing with the Versatile Platform of Graphene to Synthesize Composite Photocatalysts. Chem. Rev. 2015, 115, 10307-10377.

10. Nan, Z.; Yanhui, Z.; Min-Quan, Y.; Yi-Jun, X., Progress on Graphene-Based Composite Photocatalysts for Selective Organic Synthesis. Curr. Org. Chem. 2013, 17, 2503-2515.

11. Lang, X.; Chen, X.; Zhao, J., Heterogeneous Visible Light Photocatalysis for Selective Organic Transformations. Chem. Soc. Rev. 2014, 43, 473-486.

12. Pan, X.; Zheng, J.; Zhang, L.; Yi, Z., Core-Shell Au@SnO $\mathrm{Sn}_{2}$ Nanostructures Supported on $\mathrm{Na}_{2} \mathrm{Ti}_{4} \mathrm{O}_{9}$ Nanobelts as a Highly Active and Deactivation-Resistant Catalyst toward Selective Nitroaromatics Reduction. Inorg. Chem. 2019, 58, 11164-11171.

13. Yang, M.-Q.; Gao, M.; Hong, M.; Ho, G. W., Visible-to-NIR Photon Harvesting: Progressive Engineering of Catalysts for Solar-Powered Environmental Purification and Fuel Production. Adv. Mater. 2018, 30, 1802894. 
14. Yuliati, L.; Yoshida, H., Photocatalytic Conversion of Methane. Chem. Soc. Rev. 2008, 37, 1592-1602.

15. Wagner, F. T.; Somorjai, G. A., Photocatalytic and Photoelectrochemical Hydrogen Production on Strontium Titanate Single Crystals. J. Am. Chem. Soc. 1980, 102, 5494-5502.

16. Osterloh, F. E., Photocatalysis versus Photosynthesis: A Sensitivity Analysis of Devices for Solar Energy Conversion and Chemical Transformations. ACS Energy Lett. 2017, 2, 445-453.

17. Zhao, W.; Bai, Z.; Ren, A.; Guo, B.; Wu, C., Sunlight Photocatalytic Activity of CdS Modified TiO 2 Loaded on Activated Carbon Fibers. Appl. Surf. Sci. 2010, 256, 3493-3498.

18. Hisatomi, T.; Kubota, J.; Domen, K., Recent Advances in Semiconductors for Photocatalytic and Photoelectrochemical Water Splitting. Chem. Soc. Rev. 2014, 43, 7520-7535.

19. Han, B.; Ou, X.; Deng, Z.; Song, Y.; Tian, C.; Deng, H.; Xu, Y.-J.; Lin, Z., Nickel Metal-Organic Framework Monolayers for Photoreduction of Diluted $\mathrm{CO}_{2}$ : Metal-Node-Dependent Activity and Selectivity. Angew. Chem., Int. Ed. 2018, 57, 16811-16815.

20. Xiang, Q. J.; Yu, J. G.; Jaroniec, M., Synergetic Effect of $\mathrm{MoS}_{2}$ and Graphene as Cocatalysts for Enhanced Photocatalytic $\mathrm{H}_{2}$ Production Activity of $\mathrm{TiO}_{2}$ Nanoparticles. J. Am. Chem. Soc. 2012, 134, 6575-6578.

21. Yang, M.-Q.; Shen, L.; Lu, Y.; Chee, S. W.; Lu, X.; Chi, X.; Chen, Z.; Xu, Q.-H.; Mirsaidov, U.; Ho, G. W., Disorder Engineering in Monolayer Nanosheets Enabling Photothermic Catalysis for Full Solar Spectrum (250-2500 nm) Harvesting. Angew. Chem., Int. Ed. 2019, 58, 3077-3081.

22. Lu, H.; Zhao, J.; Li, L.; Gong, L.; Zheng, J.; Zhang, L.; Wang, Z.; Zhang, J.; Zhu, Z., Selective Oxidation of Sacrificial Ethanol over $\mathrm{TiO}_{2}$-Based Photocatalysts during Water Splitting. Energy Environ. Sci. 2011, 4, 3384-3388.

23. Zhang, H.; Wu, Y.; Li, L.; Zhu, Z., Photocatalytic Direct Conversion of Ethanol to 1,1-Diethoxyethane over Noble-Metal-Loaded $\mathrm{TiO}_{2}$ Nanotubes and Nanorods. ChemSusChem 2015, 8, 1226-1231.

24. Liu, H.; Xu, C.; Li, D.; Jiang, H. L., Photocatalytic Hydrogen Production Coupled with Selective Benzylamine Oxidation over MOF Composites. Angew. Chem. Int. Ed. 2018, 57, 5379-5383.

25. Xie, S.; Shen, Z.; Deng, J.; Guo, P.; Zhang, Q.; Zhang, H.; Ma, C.; Jiang, Z.; Cheng, J.; Deng, D.; Wang, Y., Visible Light-Driven $\mathrm{C}-\mathrm{H}$ Activation and C-C Coupling of Methanol into Ethylene Glycol. Nat. Commun. 2018, 9, 1181.

26. Dai, X.; Xie, M.; Meng, S.; Fu, X.; Chen, S., Coupled Systems for Selective Oxidation of Aromatic Alcohols to Aldehydes and Reduction of Nitrobenzene into Aniline Using CdS/g- $\mathrm{C}_{3} \mathrm{~N}_{4}$ Photocatalyst under Visible Light Irradiation. Appl. Catal. B 2014, 158-159, 382-390.

27. Shiraishi, Y.; Sugano, Y.; Tanaka, S.; Hirai, T., One-Pot Synthesis of Benzimidazoles by Simultaneous Photocatalytic and Catalytic Reactions on $\mathrm{Pt} @ \mathrm{TiO}_{2}$ Nanoparticles. Angew. Chem. Int. Ed. Engl. 2010, 49, 1656-60.

28. Shiraishi, Y.; Ikeda, M.; Tsukamoto, D.; Tanaka, S.; Hirai, T., One-Pot Synthesis of Imines from Alcohols and Amines with $\mathrm{TiO}_{2}$ Loading Pt Nanoparticles under UV Irradiation. Chem. Commun. 2011, 47, 4811-4813.

29. Zhang, H.; Xie, S.; Hu, J.; Wu, X.; Zhang, Q.; Cheng, J.; Wang, Y., C-H Activations of Methanol and Ethanol and $\mathrm{C}-\mathrm{C}$ Couplings into Diols by Zinc-Indium-Sulfide under Visible Light. Chem. Commun. 2020, 56, 1776-1779.

30. Li, F.; Wang, Y.; Du, J.; Zhu, Y.; Xu, C.; Sun, L., Simultaneous Oxidation of Alcohols and Hydrogen Evolution in a Hybrid System under Visible Light Irradiation. Appl. Catal. B 2018, 225, 258-263.

31. Jeon, T. H.; Koo, M. S.; Kim, H.; Choi, W., Dual-Functional Photocatalytic and Photoelectrocatalytic Systems for Energy- and Resource-Recovering Water Treatment. ACS Catal. 2018, 8, 11542-11563.

32. Kampouri, S.; Stylianou, K. C., Dual-Functional Photocatalysis for Simultaneous Hydrogen Production and Oxidation of Organic Substances. ACS Catal. 2019, 9, 4247-4270. 
33. Fox, M. A.; Dulay, M. T., Heterogeneous Photocatalysis. Chem. Rev. 1993, 93, 341-357.

34. Fujishima, A.; Rao, T. N.; Tryk, D. A., Titanium Dioxide Photocatalysis. J. Photochem. Photobiol. C 2000, 1, 1-21.

35. Nakata, K.; Fujishima, A., $\mathrm{TiO}_{2}$ Photocatalysis: Design and Applications. J. Photochem. Photobiol. C 2012, 13, 169-189.

36. Hou, T.; Luo, N.; Li, H.; Heggen, M.; Lu, J.; Wang, Y.; Wang, F., Yin and Yang Dual Characters of CuOx Clusters for C-C Bond Oxidation Driven by Visible Light. ACS Catal. 2017, 7, 3850-3859.

37. Ye, H.-F.; Shi, R.; Yang, X.; Fu, W.-F.; Chen, Y., P-Doped $\mathrm{Zn}_{\mathrm{x}} \mathrm{Cd}_{1-\mathrm{x}} \mathrm{S}$ Solid Solutions as Photocatalysts for Hydrogen Evolution from Water Splitting Coupled with Photocatalytic Oxidation of 5Hydroxymethylfurfural. Appl. Catal. B 2018, 233, 70-79.

38. Wang, M.; Li, L.; Lu, J.; Luo, N.; Zhang, X.; Wang, F., Photocatalytic Coupling of Amines to Imidazoles Using a Mo-ZnIn ${ }_{2} \mathrm{~S}_{4}$ Catalyst. Green Chem. 2017, 19, 5172-5177.

39. Weng, B.; Quan, Q.; Xu, Y.-J., Decorating Geometry- and Size-Controlled Sub-20 nm Pd Nanocubes

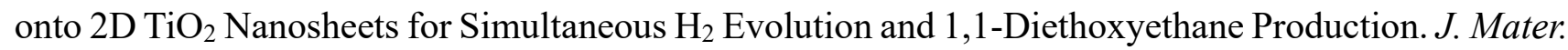
Chem. A 2016, 4, 18366-18377.

40. Roy, P.; Periasamy, A. P.; Liang, C.-T.; Chang, H.-T., Synthesis of Graphene-ZnO-Au Nanocomposites for Efficient Photocatalytic Reduction of Nitrobenzene. Environ. Sci. Technol. 2013, 47, 6688-6695.

41. Zhang, S.; Huang, W.; Fu, X.; Chen, G.; Meng, S.; Chen, S., Ultra-Low Content of Pt Modified CdS Nanorods: Preparation, Characterization, and Application for Photocatalytic Selective Oxidation of Aromatic Alcohols and Reduction of Nitroarenes in One Reaction System. J. Hazard. Mater. 2018, 360, 182-192.

42. Huang, H.; Zhao, J.; Du, Y.; Zhou, C.; Zhang, M.; Wang, Z.; Weng, Y.; Long, J.; Hofkens, J.; Steele, J. A.; Roeffaers, M. B. J., Direct Z-Scheme Heterojunction of Semicoherent $\mathrm{FAPbBr} 3 \mathrm{Bi}_{2} \mathrm{WO}_{6}$ Interface for Photoredox Reaction with Large Driving Force. ACS Nano 2020, 14, 16689-16697.

43. Liu, M.; Qiao, L.-Z.; Dong, B.-B.; Guo, S.; Yao, S.; Li, C.; Zhang, Z.-M.; Lu, T.-B., Photocatalytic coproduction of $\mathrm{H}_{2}$ and industrial chemical over MOF-derived direct Z-scheme heterostructure. Appl. Catal. B 2020, 273, 119066.

44. Jiao, Z.; Zhai, Z.; Guo, X.; Guo, X.-Y., Visible-Light-Driven Photocatalytic Suzuki-Miyaura Coupling Reaction on Mott-Schottky-type Pd/SiC Catalyst. J. Phys. Chem. C 2015, 119, 3238-3243.

45. Marszewski, M.; Cao, S.; Yu, J.; Jaroniec, M., Semiconductor-based photocatalytic $\mathrm{CO}_{2}$ conversion. Mater. Horiz. 2015, 2, 261-278.

46. Gelder, E. A.; Jackson, S. D.; Lok, C. M., The Hydrogenation of Nitrobenzene to Aniline: A New Mechanism. Chem. Commun. 2005, 522-524.

47. Toyao, T.; Saito, M.; Horiuchi, Y.; Mochizuki, K.; Iwata, M.; Higashimura, H.; Matsuoka, M., Efficient Hydrogen Production and Photocatalytic Reduction of Nitrobenzene over a Visible-Light-Responsive Metal-Organic Framework Photocatalyst. Catal. Sci. Technol. 2013, 3, 2092-2097.

48. Weng, B.; Liu, S.; Zhang, N.; Tang, Z.-R.; Xu, Y.-J., A Simple yet Efficient Visible-Light-Driven CdS Nanowires-Carbon Nanotube 1D-1D Nanocomposite Photocatalyst. J. Catal. 2014, 309, 146-155.

49. Tada, H.; Ishida, T.; Takao, A.; Ito, S., Drastic Enhancement of $\mathrm{TiO}_{2}$-Photocatalyzed Reduction of Nitrobenzene by Loading Ag Clusters. Langmuir 2004, 20, 7898-7900.

50. Füldner, S.; Pohla, P.; Bartling, H.; Dankesreiter, S.; Stadler, R.; Gruber, M.; Pfitzner, A.; König, B., Selective Photocatalytic Reductions of Nitrobenzene Derivatives Using $\mathrm{PbBiO}_{2} \mathrm{X}$ and Blue Light. Green Chem. 2011, 13, 640-643.

51. Eskandari, P.; Kazemi, F.; Zand, Z., Photocatalytic Reduction of Aromatic Nitro Compounds Using CdS Nanostructure under Blue LED Irradiation. J. Photochem. Photobiol. A: Chem. 2014, 274, 7-12.

52. Zhang, S.; Huang, W.; Fu, X.; Zheng, X.; Meng, S.; Ye, X.; Chen, S., Photocatalytic Organic 
Transformations: Simultaneous Oxidation of Aromatic Alcohols and Reduction of Nitroarenes on $\mathrm{CdLa}_{2} \mathrm{~S}_{4}$ in One Reaction System. Appl. Catal. B 2018, 233, 1-10.

53. Ning, X.; Meng, S.; Fu, X.; Ye, X.; Chen, S., Efficient Utilization of Photogenerated Electrons and Holes for Photocatalytic Selective Organic Syntheses in One Reaction System Using a Narrow Band Gap CdS Photocatalyst. Green Chem. 2016, 18, 3628-3639.

54. Ling, C.; Ye, X.; Zhang, J.; Zhang, J.; Zhang, S.; Meng, S.; Fu, X.; Chen, S., Solvothermal Synthesis of $\mathrm{CdIn}_{2} \mathrm{~S}_{4}$ Photocatalyst for Selective Photosynthesis of Organic Aromatic Compounds under Visible Light. Sci. Rep. 2017, 7, 27.

55. Nath, M.; Saini, P. K., Chemistry and Applications of Organotin(IV) Complexes of Schiff Bases. Dalton Trans. 2011, 40, 7077-7121.

56. Yao, Y.; Li, Z.-S., New Insights into the Mechanism of the Schiff Base Hydrolysis Catalyzed by Type I Dehydroquinate Dehydratase from S. Enterica: a Theoretical Study. Org. Biomol. Chem. 2012, 10, 7037-7044.

57. Higashimoto, S.; Nakai, Y.; Azuma, M.; Takahashi, M.; Sakata, Y., One-Pot Synthesis of Imine from Benzyl Alcohol and Nitrobenzene on Visible-Light Responsive CdS-TiO 2 Photocatalysts. RSC Adv. 2014, 4, 37662-37668.

58. Nakai, Y.; Azuma, M.; Muraoka, M.; Kobayashi, H.; Higashimoto, S., One-Pot Imine Synthesis from Benzylic Alcohols and Nitrobenzene on CdS-Sensitized $\mathrm{TiO}_{2}$ Photocatalysts: Effects of the Electric Nature of the Substituent and Solvents on the Photocatalytic Activity. Mol. Catal. 2017, 443, 203-208.

59. Wu, Y.; Ye, X.; Zhang, S.; Meng, S.; Fu, X.; Wang, X.; Zhang, X.; Chen, S., Photocatalytic Synthesis of Schiff Base Compounds in the Coupled System of Aromatic Alcohols and Nitrobenzene Using

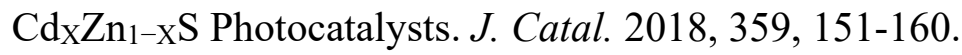

60. Yang, X.; Tao, H.; Leow, W. R.; Li, J.; Tan, Y.; Zhang, Y.; Zhang, T.; Chen, X.; Gao, S.; Cao, R., Oxygen-Vacancies-Engaged Efficient Carrier Utilization for the Photocatalytic Coupling Reaction. $J$. Catal. 2019, 373, 116-125.

61. Shi, W.; Liu, C.; Lei, A., Transition-Metal Catalyzed Oxidative Cross-Coupling Reactions to Form CC Bonds Involving Organometallic Reagents as Nucleophiles. Chem. Soc. Rev. 2011, 40, 2761-2776.

62. Sun, C.-L.; Shi, Z.-J., Transition-Metal-Free Coupling Reactions. Chem. Rev. 2014, 114, 9219-9280.

63. Cherney, A. H.; Kadunce, N. T.; Reisman, S. E., Enantioselective and Enantiospecific TransitionMetal-Catalyzed Cross-Coupling Reactions of Organometallic Reagents To Construct $\mathrm{C}-\mathrm{C}$ Bonds. Chem. Rev. 2015, 115, 9587-9652.

64. Gu, Q.; Jia, Q.; Long, J.; Gao, Z., Heterogeneous Photocatalyzed C-C Cross-coupling Reactions Under Visible-light and Near-infrared Light Irradiation. ChemCatChem 2019, 11, 669-683.

65. Xiao, Q.; Sarina, S.; Bo, A.; Jia, J.; Liu, H.; Arnold, D. P.; Huang, Y.; Wu, H.; Zhu, H., Visible LightDriven Cross-Coupling Reactions at Lower Temperatures Using a Photocatalyst of Palladium and Gold Alloy Nanoparticles. ACS Catal. 2014, 4, 1725-1734.

66. Zhang, Y.; He, S.; Guo, W.; Hu, Y.; Huang, J.; Mulcahy, J. R.; Wei, W. D., Surface-Plasmon-Driven Hot Electron Photochemistry. Chem. Rev. 2018, 118, 2927-2954.

67. Rohani, S.; Ziarati, A.; Ziarani, G. M.; Badiei, A.; Burgi, T., Engineering of Highly Active Au/Pd Supported on Hydrogenated Urchin-Like Yolk@Shell $\mathrm{TiO}_{2}$ for Visible Light Photocatalytic Suzuki Coupling. Catal. Sci. Technol. 2019, 9, 3820-3827.

68. Weng, B.; Wu, J.; Zhang, N.; Xu, Y.-J., Observing the Role of Graphene in Boosting the Two-Electron Reduction of Oxygen in Graphene--WO 3 Nanorod Photocatalysts. Langmuir 2014, 30, 5574-5584.

69. Han, C.; Zhang, N.; Xu, Y.-J., Structural Diversity of Graphene Materials and Their Multifarious Roles in Heterogeneous Photocatalysis. Nano Today 2016, 11, 351-372.

70. Weng, B.; Xu, Y.-J., What if the Electrical Conductivity of Graphene Is Significantly Deteriorated for 
the Graphene-Semiconductor Composite-Based Photocatalysis? ACS Appl. Mater. Interfaces 2015, 7, 27948-27958.

71. Weng, B.; Yang, M.-Q.; Zhang, N.; Xu, Y.-J., Toward the Enhanced Photoactivity and Photostability of $\mathrm{ZnO}$ Nanospheres via Intimate Surface Coating with Reduced Graphene Oxide. J. Mater. Chem. A 2014, 2, 9380-9389.

72. Li, Y.; Zhang, Z.; Pei, L.; Li, X.; Fan, T.; Ji, J.; Shen, J.; Ye, M., Multifunctional Photocatalytic Performances of Recyclable Pd-NiFe $\mathrm{O}_{4} /$ Reduced Graphene Oxide Nanocomposites via Different CoCatalyst Strategy. Appl. Catal. B 2016, 190, 1-11.

73. Gao, S.; Shang, N.; Feng, C.; Wang, C.; Wang, Z., Graphene Oxide-Palladium Modified Ag-AgBr: a Visible-Light-Responsive Photocatalyst for the Suzuki Coupling Reaction. RSC Adv. 2014, 4, 3924239247.

74. Li, Z.; Pi, Y.; Xu, D.; Li, Y.; Peng, W.; Zhang, G.; Zhang, F.; Fan, X., Utilization of $\mathrm{MoS}_{2}$ and Graphene to Enhance the Photocatalytic Activity of $\mathrm{Cu}_{2} \mathrm{O}$ for Oxidative C-C Bond Formation. Appl. Catal. B 2017, 213, 1-8.

75. Zhao, Y.; Antonietti, M., Visible-Light-Irradiated Graphitic Carbon Nitride Photocatalyzed DielsAlder Reactions with Dioxygen as Sustainable Mediator for Photoinduced Electrons. Angew. Chem., Int. Ed. 2017, 56, 9336-9340.

76. Rueping, M.; Zoller, J.; Fabry, D. C.; Poscharny, K.; Koenigs, R. M.; Weirich, T. E.; Mayer, J., LightMediated Heterogeneous Cross Dehydrogenative Coupling Reactions: Metal Oxides as Efficient, Recyclable, Photoredox Catalysts in C C Bond-Forming Reactions. Chem.-Eur. J 2012, 18, 34783481.

77. Zhang, W.-Q.; Li, Q.-Y.; Zhang, Q.; Lu, Y.; Lu, H.; Wang, W.; Zhao, X.; Wang, X.-J., Robust MetalOrganic Framework Containing Benzoselenadiazole for Highly Efficient Aerobic Crossdehydrogenative Coupling Reactions under Visible Light. Inorg. Chem. 2016, 55, 1005-1007.

78. Mitkina, T.; Stanglmair, C.; Setzer, W.; Gruber, M.; Kisch, H.; König, B., Visible Light Mediated Homo- and Heterocoupling of Benzyl Alcohols and Benzyl Amines on Polycrystalline Cadmium Sulfide. Org. Biomol. Chem. 2012, 10, 3556-3561.

79. Shin, H. H.; Kang, E.; Park, H.; Han, T.; Lee, C.-H.; Lim, D.-K., Pd-Nanodot Decorated MoS Nanosheets as a Highly Efficient Photocatalyst for the Visible-Light-Induced Suzuki-Miyaura Coupling Reaction. J. Mater. Chem. A 2017, 5, 24965-24971.

80. Wang, B.; Guo, X.; Jin, G.; Guo, X., Visible-Light-Enhanced Photocatalytic Sonogashira Reaction over Silicon Carbide Supported Pd Nanoparticles. Catal. Commun. 2017, 98, 81-84.

81. Wang, B.; Wang, Y.; Li, J.; Guo, X.; Bai, G.; Tong, X.; Jin, G.; Guo, X., Photocatalytic Sonogashira Reaction over Silicon Carbide Supported $\mathrm{Pd}-\mathrm{Cu}$ Alloy Nanoparticles under Visible Light Irradiation. Catal. Sci. Technol. 2018, 8, 3357-3362.

82. Xie, A.; Zhang, K.; Wu, F.; Wang, N.; Wang, Y.; Wang, M., Polydopamine Nanofilms as Visible LightHarvesting Interfaces for Palladium Nanocrystal Catalyzed Coupling Reactions. Catal. Sci. Technol. 2016, 6, 1764-1771.

83. Wang, Z. J.; Ghasimi, S.; Landfester, K.; Zhang, K. A. I., Photocatalytic Suzuki Coupling Reaction Using Conjugated Microporous Polymer with Immobilized Palladium Nanoparticles under Visible Light. Chem. Mater. 2015, 27, 1921-1924.

84. Yang, C.; Wang, B.; Zhang, L.; Yin, L.; Wang, X., Synthesis of Layered Carbonitrides from Biotic Molecules for Photoredox Transformations. Angew. Chem., Int. Ed. 2017, 56, 6627-6631.

85. Li, X.-H.; Baar, M.; Blechert, S.; Antonietti, M., Facilitating Room-Temperature Suzuki Coupling Reaction with Light: Mott-Schottky Photocatalyst for C-C-Coupling. Sci. Rep. 2013, 3, 1743.

86. Filippini, G.; Longobardo, F.; Forster, L.; Criado, A.; Di Carmine, G.; Nasi, L.; D’Agostino, C.; 
Melchionna, M.; Fornasiero, P.; Prato, M., Light-driven, heterogeneous organocatalysts for C-C bond formation toward valuable perfluoroalkylated intermediates. Sci. Adv. 2020, 6, eabc9923.

87. Ghosh, I.; Khamrai, J.; Savateev, A.; Shlapakov, N.; Antonietti, M.; König, B., Organic semiconductor photocatalyst can bifunctionalize arenes and heteroarenes. Science 2019, 365, 360-366.

88. Rahimi, A.; Ulbrich, A.; Coon, J. J.; Stahl, S. S., Formic-Acid-Induced Depolymerization of Oxidized Lignin to Aromatics. Nature 2014, 515, 249-252.

89. Ferrini, P.; Rinaldi, R., Catalytic Biorefining of Plant Biomass to Non-Pyrolytic Lignin Bio-Oil and Carbohydrates through Hydrogen Transfer Reactions. Angew. Chem., Int. Ed. 2014, 53, 8634-8639.

90. Nguyen, J. D.; Matsuura, B. S.; Stephenson, C. R., A Photochemical Strategy for Lignin Degradation at Room Temperature. J. Am. Chem. Soc. 2014, 136, 1218-21.

91. Luo, N.; Wang, M.; Li, H.; Zhang, J.; Liu, H.; Wang, F., Photocatalytic Oxidation-Hydrogenolysis of Lignin $\beta$-O-4 Models via a Dual Light Wavelength Switching Strategy. ACS Catal. 2016, 6, 7716-7721.

92. Liu, H.; Li, H.; Lu, J.; Zeng, S.; Wang, M.; Luo, N.; Xu, S.; Wang, F., Photocatalytic Cleavage of C-C Bond in Lignin Models under Visible Light on Mesoporous Graphitic Carbon Nitride through $\pi-\pi$ Stacking Interaction. ACS Catal. 2018, 8, 4761-4771.

93. Luo, N.; Wang, M.; Li, H.; Zhang, J.; Hou, T.; Chen, H.; Zhang, X.; Lu, J.; Wang, F., Visible-LightDriven Self-Hydrogen Transfer Hydrogenolysis of Lignin Models and Extracts into Phenolic Products. ACS Catal. 2017, 7, 4571-4580.

94. Lin, J.; Wu, X.; Xie, S.; Chen, L.; Zhang, Q.; Deng, W.; Wang, Y., Visible-Light-Driven Cleavage of C-O Linkage for Lignin Valorization to Functionalized Aromatics. ChemSusChem 2019, 12, 50235031.

95. Wu, X.; Fan, X.; Xie, S.; Lin, J.; Cheng, J.; Zhang, Q.; Chen, L.; Wang, Y., Solar Energy-Driven LigninFirst Approach to Full Utilization of Lignocellulosic Biomass under Mild Conditions. Nat. Catal. 2018, 1, 772-780.

96. Chai, Z.; Zeng, T.-T.; Li, Q.; Lu, L.-Q.; Xiao, W.-J.; Xu, D., Efficient Visible Light-Driven Splitting of Alcohols into Hydrogen and Corresponding Carbonyl Compounds over a Ni-Modified CdS Photocatalyst. J. Am. Chem. Soc. 2016, 138, 10128-10131.

97. Higashimoto, S.; Tanaka, Y.; Ishikawa, R.; Hasegawa, S.; Azuma, M.; Ohue, H.; Sakata, Y., Selective Dehydrogenation of Aromatic Alcohols Photocatalyzed by Pd-Deposited $\mathrm{CdS}-\mathrm{TiO}_{2}$ in Aqueous Solution Using Visible Light. Catal. Sci. Technol. 2013, 3, 400-403.

98. Han, C.; Tang, Z.-R.; Liu, J.; Jin, S.; Xu, Y.-J., Efficient Photoredox Conversion of Alcohol to Aldehyde and $\mathrm{H}_{2}$ by Heterointerface Engineering of Bimetal-Semiconductor Hybrids. Chem. Sci. 2019, 10, 35143522 .

99. Chen, L. H.; Zhu, X. W.; Wang, F. D.; Gu, W. Z., Photoproduction Of Hydrogen And 1,2-Propanediol From Aqueous-Methanol And Ethanol Solution Catalyzed by ZnS. J. Photoch. Photobio. A 1993, 73, 217-220.

100.Ye, X.; Chen, Y.; Wu, Y.; Zhang, X.; Wang, X.; Chen, S., Constructing a System for Effective Utilization of Photogenerated Electrons and Holes: Photocatalytic Selective Transformation of Aromatic Alcohols to Aromatic Aldehydes and Hydrogen Evolution over $Z_{3} \operatorname{In}_{2} \mathrm{~S}_{6}$ Photocatalysts. Appl. Catal. B 2019, 242, 302-311.

101.Antoniadou, M.; Vaiano, V.; Sannino, D.; Lianos, P., Photocatalytic Oxidation of Ethanol Using Undoped and Ru-Doped Titania: Acetaldehyde, Hydrogen or Electricity Generation. Chem. Eng. J. 2013, 224, 144-148.

102.Imamura, K.; Tsukahara, H.; Hamamichi, K.; Seto, N.; Hashimoto, K.; Kominami, H., Simultaneous Production of Aromatic Aldehydes and Dihydrogen by Photocatalytic Dehydrogenation of Liquid Alcohols over Metal-Loaded Titanium(IV) Oxide under Oxidant- and Solvent-Free Conditions. Appl. 
Catal., A 2013, 450, 28-33.

103.Zhang, L.; Jiang, D.; Irfan, R. M.; Tang, S.; Chen, X.; Du, P., Highly Efficient and Selective Photocatalytic Dehydrogenation of Benzyl Alcohol for Simultaneous Hydrogen and Benzaldehyde Production over Ni-Decorated $\mathrm{Zn}_{0.5} \mathrm{Cd}_{0.5} \mathrm{~S}$ Solid Solution. J. Energy Chem. 2019, 30, 71-77.

104.Zhu, T.; Ye, X.; Zhang, Q.; Hui, Z.; Wang, X.; Chen, S., Efficient Utilization of Photogenerated Electrons and Holes for Photocatalytic Redox Reactions Using Visible Light-Driven $\mathrm{Au} / \mathrm{ZnIn}_{2} \mathrm{~S}_{4}$ Hybrid. J. Hazard. Mater. 2019, 367, 277-285.

105.Jiang, D.; Chen, X.; Zhang, Z.; Zhang, L.; Wang, Y.; Sun, Z.; Irfan, R. M.; Du, P., Highly Efficient Simultaneous Hydrogen Evolution and Benzaldehyde Production using Cadmium Sulfide Nanorods Decorated with Small Cobalt Nanoparticles under Visible Light. J. Catal. 2018, 357, 147-153.

106.Liu, Z.; Caner, J.; Kudo, A.; Naka, H.; Saito, S., Redox-Selective Generation of Aldehydes and $\mathrm{H}_{2}$ From Alcohols under Visible Light. Chem. Eur. J. 2013, 19, 9452-6.

107.Kasap, H.; Caputo, C. A.; Martindale, B. C. M.; Godin, R.; Lau, V. W.-h.; Lotsch, B. V.; Durrant, J. R.; Reisner, E., Solar-Driven Reduction of Aqueous Protons Coupled to Selective Alcohol Oxidation with a Carbon Nitride-Molecular Ni Catalyst System. J. Am. Chem. Soc. 2016, 138, 9183-9192.

108.Li, Y.-H.; Zhang, F.; Chen, Y.; Li, J.-Y.; Xu, Y.-J., Photoredox-Catalyzed Biomass Intermediate Conversion Integrated with $\mathrm{H}_{2}$ Production over $\mathrm{Ti}_{3} \mathrm{C}_{2} \mathrm{~T}_{\mathrm{x}} / \mathrm{CdS}$ Composites. Green Chem. 2020, 22, 163 169.

109.Tsunehiro, T.; Sakae, T.; Takuzo, F.; Satohiro, Y., Selective Formation of Acetal by Photooxidation of Ethanol over Silica-supported Niobium Oxide Catalysts. Chem. Lett. 1994, 23, 809-812.

110.Zhang, S.; Chang, C.; Huang, Z.; Ma, Y.; Gao, W.; Li, J.; Qu, Y., Visible-Light-Activated SuzukiMiyaura Coupling Reactions of Aryl Chlorides over the Multifunctional Pd/Au/Porous Nanorods of $\mathrm{CeO}_{2}$ Catalysts. ACS Catal. 2015, 5, 6481-6488.

111. Yanagida, S.; Azuma, T.; Kawakami, H.; Kizumoto, H.; Sakurai, H., Photocatalytic Carbon-Carbon Bond Formation with Concurrent Hydrogen Evolution on Colloidal Zinc Sulphide. J. Chem. Soc., Chem. Commun. 1984, 21-22.

112.Yang, P.; Zhao, J.; Cao, B.; Li, L.; Wang, Z.; Tian, X.; Jia, S.; Zhu, Z., Selective Photocatalytic C-C Coupling of Bioethanol into 2,3-Butanediol over Pt-Decorated Hydroxyl-Group-Tunable $\mathrm{TiO}_{2}$ Photocatalysts. ChemCatChem 2015, 7, 2384-2390.

113.Zhou, P.; Chao, Y.; Lv, F.; Wang, K.; Zhang, W.; Zhou, J.; Chen, H.; Wang, L.; Li, Y.; Zhang, Q., Metal Single Atom Strategy Greatly Boosts Photocatalytic Methyl Activation and $\mathrm{C}-\mathrm{C}$ Coupling for the Coproduction of High-Value-Added Multicarbon Compounds and Hydrogen. ACS Catal. 2020, 10, 9109-9114.

114.Wang, J.; Yang, P.; Cao, B.; Zhao, J.; Zhu, Z., Photocatalytic Carbon-Carbon Bond Formation with Concurrent Hydrogen Evolution on the Pt/TiO ${ }_{2}$ Nanotube. Appl. Surf. Sci. 2015, 325, 86-90.

115.Lu, H.; Zhao, B.; Zhang, D.; Lv, Y.; Shi, B.; Shi, X.; Wen, J.; Yao, J.; Zhu, Z., Room Temperature Aqueous Solution Synthesis of Pinacol $\left(\mathrm{C}_{6}\right)$ by Photocatalytic C-C Coupling of Isopropanol. $J$. Photochem. Photobiol. A: Chem. 2013, 272, 1-5.

116.Cao, B.; Yu, Y.; Xu, S.; Qu, J.; Gao, G.; Li, H.; Gao, N.; Ren, Y.; Zhou, C., Selective photocatalytic C$\mathrm{C}$ coupling of isopropanol into pinacol with concurrent hydrogen evolution over $\mathrm{GONaOH}$ photocatalyst. New J. Chem. 2019, 43, 1936-1942.

117.Agosti, A.; Nakibli, Y.; Amirav, L.; Bergamini, G., Photosynthetic $\mathrm{H}_{2}$ generation and organic transformations with CdSe@CdS-Pt nanorods for highly efficient solar-to-chemical energy conversion. Nano Energy 2020, 70, 104510.

118.Chao, Y.; Zhang, W.; Wu, X.; Gong, N.; Bi, Z.; Li, Y.; Zheng, J.; Zhu, Z.; Tan, Y., Visible-Light Direct Conversion of Ethanol to 1,1-Diethoxyethane and Hydrogen over a Non-Precious Metal Photocatalyst. 
Chem.-Eur. J 2019, 25, 189-194.

119.Chao, Y.; Lai, J.; Yang, Y.; Zhou, P.; Zhang, Y.; Mu, Z.; Li, S.; Zheng, J.; Zhu, Z.; Tan, Y., Visible LightDriven Methanol Dehydrogenation and Conversion into 1,1-Dimethoxymethane over a Non-Noble Metal Photocatalyst under Acidic Conditions. Catal. Sci. Technol. 2018, 8, 3372-3378.

120.Zhang, H.; Zhang, W.; Zhao, M.; Yang, P.; Zhu, Z., A Site-Holding Effect of $\mathrm{TiO}_{2}$ Surface Hydroxyl in the Photocatalytic Direct Synthesis of 1,1-Diethoxyethane from Ethanol. Chem. Commun. 2017, 53, 1518-1521.

121.Cao, S.; Chen, Y.; Hou, C.-C.; Lv, X.-J.; Fu, W.-F., Cobalt Phosphide as a Highly Active Non-Precious Metal Cocatalyst for Photocatalytic Hydrogen Production under Visible Light Irradiation. J. Mater. Chem. A 2015, 3, 6096-6101.

122.Han, G.; Jin, Y. H.; Burgess, R. A.; Dickenson, N. E.; Cao, X. M.; Sun, Y., Visible-Light-Driven Valorization of Biomass Intermediates Integrated with $\mathrm{H}_{2}$ Production Catalyzed by Ultrathin $\mathrm{Ni} / \mathrm{CdS}$ Nanosheets. J. Am. Chem. Soc. 2017, 139, 15584-15587.

123.Luo, N.; Montini, T.; Zhang, J.; Fornasiero, P.; Fonda, E.; Hou, T.; Nie, W.; Lu, J.; Liu, J.; Heggen, M.; Lin, L.; Ma, C.; Wang, M.; Fan, F.; Jin, S.; Wang, F., Visible-Light-Driven Coproduction of Diesel Precursors and Hydrogen from Lignocellulose-Derived Methylfurans. Nat. Energy 2019, 4, 575-584.

124.Uekert, T.; Dorchies, F.; Pichler, C. M.; Reisner, E., Photoreforming of food waste into value-added products over visible-light-absorbing catalysts. Green Chem. 2020, 22, 3262-3271.

125.Guo, Q.; Liang, F.; Li, X.-B.; Gao, Y.-J.; Huang, M.-Y.; Wang, Y.; Xia, S.-G.; Gao, X.-Y.; Gan, Q.-C.; Lin, Z.-S.; Tung, C.-H.; Wu, L.-Z., Efficient and Selective $\mathrm{CO}_{2}$ Reduction Integrated with Organic Synthesis by Solar Energy. Chem 2019, 5, 2605-2616.

126.Yang, T.; Yu, Q.; Wang, H., Photocatalytic Reduction of $\mathrm{CO}_{2}$ to $\mathrm{CH}_{3} \mathrm{OH}$ Coupling with the Oxidation of Amine to Imine. Chem. Lett. 2018, 148, 2382-2390.

127.Wang, L.; Zhang, X.; Yang, L.; Wang, C.; Wang, H., Photocatalytic Reduction of $\mathrm{CO}_{2} \mathrm{Coupled}_{\text {with }}$ Selective Alcohol Oxidation under Ambient Conditions. Catal. Sci. Technol. 2015, 5, 4800-4805.

128. Yuan, L.; Li, Y.-H.; Tang, Z.-R.; Gong, J.; Xu, Y.-J., Defect-promoted visible light-driven C-C coupling reactions pairing with $\mathrm{CO}_{2}$ reduction. J. Catal. 2020, 390, 244-250. 
Table of Content (TOC)

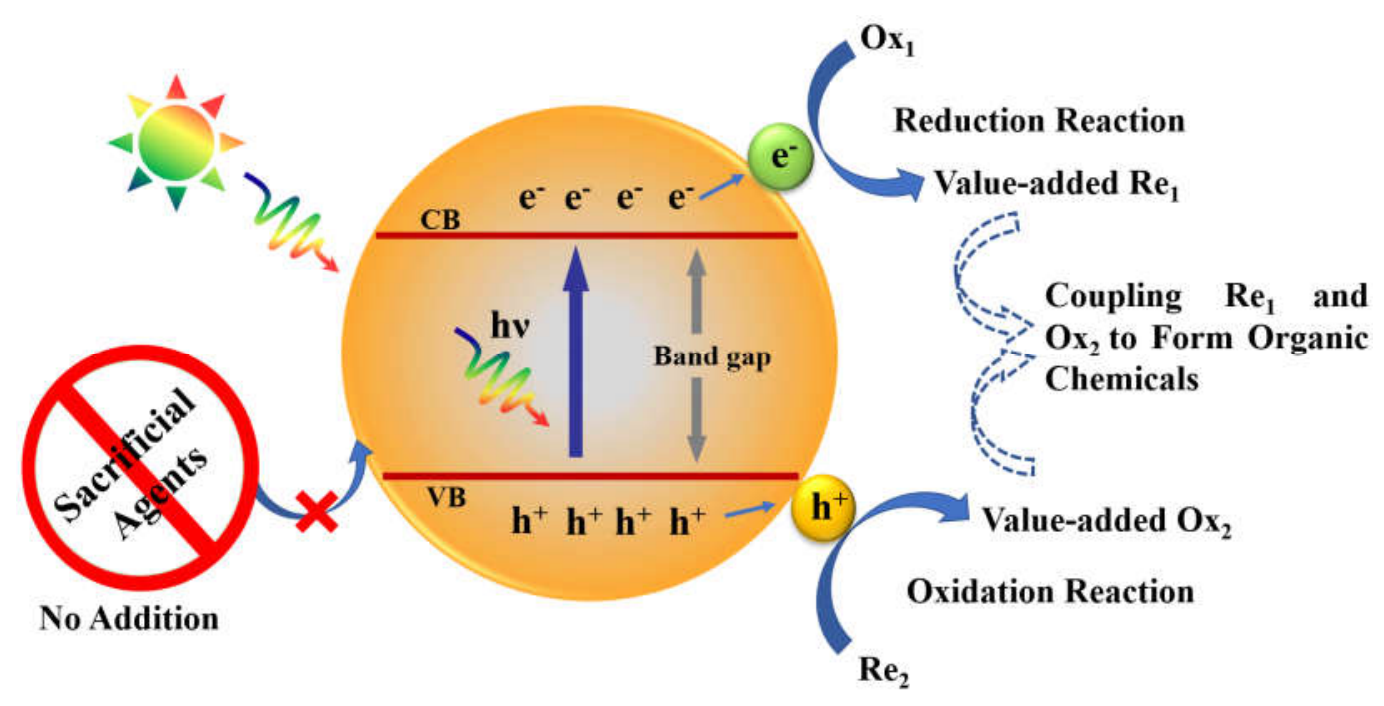

